\title{
Origen y evolución de las patentes y marcas en biomecánica deportiva Origin and evolution of patents and trademarks in sports biomechanics
}

\author{
José Luis González-Montesinos y Jorge del Rosario Fernández-Santos \\ Universidad de Cádiz
}

\begin{abstract}
Resumen
La Biomecánica es una disciplina científica cuyo origen se remonta varios siglos atrás, cuando distintos precursores utilizaron diferentes ciencias para analizar el movimiento humano y animal. El desarrollo tecnológico ha propiciado la invención de distintos dispositivos los cuales han sido utilizados en estudios biomecánicos. Dichos dispositivos han facilitado la toma y análisis de datos relacionados con el movimiento y sus causas. La Oficina Española de Patentes y Marcas (O.E.P.M.) es el organismo encargado de registrar y patentar las invenciones en España. Para ello, la patente presentada debe de cumplir con unos requisitos y superar una evaluación técnica. Actualmente podemos encontrar distintas patentes para realizar análisis cinemáticos y cinéticos del movimiento, formadas por emisores y receptores de láser, cámaras de alta velocidad, sensores de presión, etc. Numerosas investigaciones relacionadas con la biomecánica deportiva utilizan estos dispositivos para obtener datos más precisos, mejorando la calidad de la investigación y, en algunos casos, posibilitando la mejora del rendimiento físico y/o deportivo. El propósito del presente artículo, consiste en exponer la evolución de la biomecánica en general, y deportiva en particular, realizando una revisión sobre patentes relacionadas con la biomecánica del deporte, y reflejar cómo y donde registrar las invenciones. Para ello se han utilizado las plataformas digitales y bases de datos Esp@cenet, Invesnes para la revisión de patentes con origen español y, Google Patent para patentes registradas en oficinas de fuera de España.
\end{abstract}

Palabras clave: biomecánica; deporte; medición; patentes.

\begin{abstract}
We can consider that the biomechanics is a science discipline that originated centuries ago when various scientists used mathematics to analyze human and animal movement. Technological development has led to the invention of various devices which have been used in biomechanical studies. Such devices have facilitated the collection and analysis of data related to the movement and its causes. The Spanish Patent and Trademark Office (O.E.P.M.) is the agency responsible for registering and patenting inventions in Spain. This patent submitted must meet requirements and pass a technical examination. Today we can find various patents for kinematic and kinetic analysis of the movement, formed by laser transmitters and receivers, high speed cameras or pressure sensors. Most research related to sports biomechanics using these devices for more accurate data, improve the quality of the research and improving the physical performance. The purpose of this review article is to show the evolution of biomechanics in general and sports in particular, a number of patents registered in the O.E.P.M. and an explanation of how and where to register inventions. To do this we used the digital platform Esp@cenet, Invesnes for the revision of spanish origin and patents Google Patent for patents registered offices outside Spain.
\end{abstract}

Key words: biomechanics: sport; measurement; patents.

Correspondencia/correspondence: José L. González-Montesinos

Universidad de Cádiz. España

E-mail: jgmontesinos@uca.es 


\section{Introducción}

A ctualmente son numerosas las investigaciones sobre el origen y evolución de la Biomecánica, destacando los estudios de Aguado, Izquierdo, y González (1997), donde se refleja dicho término como "disciplina que utiliza los principios y métodos de la mecánica para el estudio de los seres vivos, teniendo en cuenta sus peculiaridades”. Dentro de las ramas de la biomecánica se encuentra la biomecánica humana, la cual se desarrolla en tres diferentes campos: el médico, ocupacional y deportivo (Vera, 1989). Dentro de la biomecánica humana y gracias al desarrollo científico, se han ideado y fabricado numerosos dispositivos que facilitaron el registro del movimiento deportivo, la toma de datos en situación real y la creación de estudios científicos que posibilitaron el avance de la biomecánica del deporte.

Hoy día, en España, los dispositivos de valoración del movimiento humano desde la perspectiva de la biomecánica del deporte, suelen ser desarrollados por grandes centros de investigación, públicos y privados, como son las distintas Universidades y Departamentos, Centros de Investigación Científica, Centro de Estudios de Investigaciones Técnicas (C.E.I.T.) y Centros de Alto Rendimiento (C.A.R.).

La instrumentación, producto de la capacidad científica, creativa e innovadora de sus autores, ha requerido, en la mayoría de los casos, un registro que garantizan su novedad, divulgación al resto de la comunidad científica y posibilidades de explotación. Tal registro de la actividad inventiva es realizado en España y previa petición de persona física o jurídica, por medio de la Oficina Española de Patentes y Marcas (O.E.P.M., 2012 a).

Como objetivos del presente artículo de revisión, destaca la búsqueda de aquellas patentes más representativas que puedan estar relacionadas con la biomecánica deportiva, así como dar a conocer la forma y procesos para llevar a cabo el registro de la invención. En el año 2003, la Organización Mundial de la Propiedad Intelectual (O.M.P.I.), la Oficina Europea de Patentes (E.P.O.), la O.E.P.M. y numerosas oficinas nacionales de países latinoamericanos asumieron el reto de poner a disposición del público un importante acervo de información tecnológica en castellano y portugués, contenida en los documentos de patentes publicadas por todas ellas. Este programa fue denominado LATIPAT y utiliza la plataforma de Esp@cenet e Invesnes (O.E.P.M., 2012 b), siendo por tanto estos sistemas, entre otros como Google Patent, fundamentales en la presente estrategia de revisión.

\section{Oficina española de patentes y marcas (O.E.P.M.).}

La O.E.P.M. es un organismo autónomo del Ministerio de Industria, Energía y Turismo que, entre otras funciones, otorga protección jurídica a las diferentes modalidades de propiedad industrial mediante la concesión de patentes, modelos de utilidad, diseños industriales, marcas y nombres comerciales. A nivel internacional representa a España ante las distintas organizaciones internacionales que se encargan de la propiedad industrial e intelectual.

Cabe señalar la diferenciación entre solicitud de Marca y Nombre Comercial:

- Marca, es un título que concede el derecho exclusivo a la utilización de un signo para la identificación de un producto o un servicio en el mercado, como puede ser las palabras o combinaciones de éstas, imágenes, figuras, símbolos, gráficos, letras, cifras, formas tridimensionales (envoltorios, envases, formas del producto o su representación).

- Nombre comercial, es un título que concede el derecho exclusivo a la utilización de cualquier signo o denominación como identificador de una empresa en el tráfico mercantil (O.E.P.M. e). Así por ejemplo, la palabra-distintivo “Biolasersport” (Ferro, 2012), asociado a 
la patente descrita posteriormente, "Sistema de análisis cinemático para entrenamientos y competiciones deportivas” (Ferro y Floria, 2010) ha sido publicada en B.O.P.I. y aceptada como Marca Nacional, aparte de su solicitud como Patente. El Nombre Comercial identifica a una sociedad, a diferencia de la marca que identifica el producto. Por otro lado, el Nombre Comercial lleva al final las siglas que identifica el tipo de sociedad sobre la cual se fundó, por ejemplo: Biomecánica y Ergonomía, Sociedad Limitada (S.L).

Patentes: Definición, Requisitos y Patentes Internacionales.

Previo examen de las solicitudes enviadas, la O.E.P.M., concede los diversos títulos de propiedad industrial y ofrece servicios de información tecnológica basados en la información de las distintas modalidades de propiedad industrial ya concedidas propiamente, así como por otras oficinas extranjeras.

A continuación se reflejan aspectos claves que hay que tener en cuenta en el momento de solicitar una patente, desde conocer exactamente a que modalidad de registro hace referencia, hasta cómo solicitarla y los pasos a seguir hasta su concesión (O.E.P.M., 2012 d).

\section{¿Qué es una patente?}

Una Patente es un título que reconoce el derecho de explotar en exclusiva una invención, impidiendo a otros su fabricación, venta o utilización sin consentimiento del titular. Su solicitud puede realizarla cualquier persona física o jurídica o mediante un agente de la propiedad industrial o representante debidamente autorizados.

La solicitud de patente puede realizarse en la misma O.E.P.M., registros de cualquier órgano administrativo de la Administración General del Estado, de cualquier Administración de las CC.AA, en las Oficinas de Correos, en las representaciones diplomáticas u oficinas consulares de España en el extranjero o incluso a través de Internet, por medio de un programa informático denominado Online Filing (O.E.P.M. 2012 e).

Requisitos debe cumplir una patente (O.E.P.M. 2012 f):

Según la Ley Española de Patentes L.P.E. (1986), para que una invención pueda ser objeto de patente debe reunir tres requisitos:

1. Novedad inventiva: Se considera que una invención es nueva cuando no está comprendida en el estado de la técnica; es decir que antes no ha sido registrado por otro usuario.

2. Actividad inventiva: Se considera que una invención implica actividad inventiva si aquélla no resulta del estado de la técnica de una manera evidente para un experto en la materia.

3. Aplicación industrial: Se considera que una invención es susceptible de aplicación industrial cuando su objeto puede ser fabricado mediante técnicas industriales.

Siguiendo estas directrices, no se consideran invenciones, tal y como refleja el Art. 4.4 L.P.E. (Ley Española de Patentes, 1986), los descubrimientos, las teorías científicas y los métodos matemáticos, las obras literarias o artísticas o cualquier otra creación estética, así como las obras científicas, los planes, reglas y métodos para el ejercicio de actividades intelectuales, para juegos o para actividades económico-comerciales, así como los programas de ordenador ni las formas de presentar información.

Tampoco pueden ser objeto de patente las invenciones cuya publicación o explotación sea contraria al orden público o a las buenas costumbres, así por ejemplo se incluyen aquí los procedimientos de clonación de seres humanos, la utilización de embriones con fines industriales o comerciales y los procedimientos de modificación de la identidad genética de 
animales que supongan para éstos sufrimientos sin utilidad médica o veterinaria sustancial para el hombre o el animal, entre otros (Art. 5, Ley Española de Patentes, 1986).

Una vez cumplidos con los requisitos previos se puede proceder al proceso de tramitación de una solicitud de patente. Existen dos procedimientos de tramitación, un procedimiento general, en el que se elabora un Informe sobre el Estado de la Técnica (I.E.T), y que contiene una lista de divulgaciones anteriores iguales o similares a la invención presentada o bien mediante procedimiento de concesión con examen previo, en el que además del I.E.T. se realiza un examen de fondo de los requisitos de novedad y actividad inventiva.

Sea cual sea el procedimiento elegido existe un proceso común en el cual se ha de entregar un documento que debe contener el título de la invención, los datos del solicitante, una descripción de la invención, una o varias reivindicaciones y el justificante de pago de la tasa correspondiente. Transcurridos dieciocho meses desde la fecha de presentación y una vez superado el examen técnico, la O.E.P.M. pone a disposición del público la solicitud de patente y se abre un plazo de dos meses para que cualquier tercera persona pueda formular observaciones sobre la novedad y la actividad inventiva de la invención.

Finalizado el plazo señalado y si lo presentado se ajusta a la normativa, la O.E.P.M. procede a la concesión de la patente, anunciándolo en el B.O.P.I. y se expide el correspondiente Título de Patente. Una vez concedida tiene una duración de veinte años improrrogables, contados a partir de la fecha de presentación de la solicitud y produce sus efectos desde el día en que se publica la mención de la concesión en el B.O.P.I. (Arts. 49 y 50 Ley Española de Patentes, 1986).

El proceso de patente, aunque puede alargarse durante un tiempo prolongado hasta obtener la concesión definitiva, está siendo facilitado por la O.E.P.M., tanto el proceso de presentación de solicitudes como la disminución de las tasas básicas de presentación de solicitudes, tanto para un investigador particular, como para una institución, estando las universidades públicas, exentas de pago.

\section{¿Qué es una solicitud internacional (P.C.T.)?}

El procedimiento P.C.T. ("Patent Cooperation Treaty") es un procedimiento de patente que posibilita la protección de las invenciones cuando dicha protección se desea obtener en varios países, estableciendo un sistema por el que la presentación de una solicitud única produce los mismos efectos que si dicha solicitud hubiera sido presentada en cada uno de los países que forman parte del Tratado P.C.T., compuesto por más de 130 países. Sus ventajas radican en que es un sistema por el que se unifica la tramitación previa a la concesión y permite al solicitante retrasar el comienzo de la tramitación de su solicitud en cada una de las oficinas designadas, con el consiguiente ahorro de tiempo y dinero. Además, le permite disponer con antelación del informe de búsqueda internacional relativo a su solicitud y conocer el estado de la técnica relevante para su invención y valorar si su solicitud dispone realmente de actividad inventiva. Así pues, este procedimiento permite "comprar tiempo", ya que retrasa su decisión de entrar en la fase nacional hasta 30 meses desde la fecha de presentación internacional o de prioridad, y mantener en secreto su invento un mínimo de 18 meses. Es evidente la importante ventaja que representa la amplia protección de la invención a todos los países del tratado, que protege la invención ante posibles copias o plagios en numerosos países. Aquellas patentes registradas como internacionales reflejan una fecha de publicación internacional y un número de solicitud precedido por las siglas PCT o WO. La O.E.P.M. actúa como oficina receptora de las solicitudes internacionales P.C.T. cuyos titulares sean españoles o con residencia en España (O.E.P.M., 2012 g). 


\section{Origen y evolución de la tecnología en la biomecánica}

Siguiendo a Izquierdo (2008) podemos considerar diferentes etapas históricas las cuales han tenido importancia científica para el desarrollo de la biomecánica en general. A continuación exponemos a modo de resumen las más representativas:

Podemos considerar que ya en la Antigüedad (650 a.C.-200d.C.) grandes precursores como Aristóteles (384-322 a.C.), Arquímedes (287-212 a.C.) o Galeno (129-201 d.C.) aportaron paradigmas matemáticos, mecánicos y anatómicos que sirvieron para el desarrollo de la biomecánica.

Más recientemente durante los periodos del Renacimiento italiano (1450-1600), la Revolución Científica (1600-1730) y la Ilustración (1730-1800) grandes científicos como Leonardo Da Vinci (1452-1519), Vesalio (1514-1564), Galileo Galilei (1564-1642), Alfonso Borelli (1608-1679), Isaac Newton (1642-1727), Leonard Euler (1707-1783) o Joseph Lagrange (1736-1815) sentaron las bases de la biomecánica moderna (Aguado, Izquierdo y González, 1997), a través del estudio del concepto de fuerza, las acciones musculares, y las leyes mecánicas del movimiento las cuales permitieron a través del análisis matemático el estudio de la dinámica de los movimientos humanos.

Sin embargo no es hasta el siglo XIX cuando encontramos el desarrollo de distintos instrumentos para estudiar el movimiento de los cuales destacamos la cámara fotográfica como primer dispositivo tecnológico utilizado en el estudio del movimiento humano. La cámara fotográfica fue utilizada por primera vez por Joseph Nicéphore Nièpce (1765-1833) en 1816 para obtener fotografías en papel.

Etienne Jules Marey (1838-1904) y Edward Muybridge (1830-1904) fueron los precursores, dentro de la biomecánica, del uso de las cámaras fotográficas para el análisis del movimiento. Marey aportó numerosos inventos para perfeccionar el estudio del movimiento a través de la cinematografía como por ejemplo el Fusil fotográfico, el cual le permitía obtener múltiples imágenes de objetos en movimientos en intervalos de tiempo iguales. También utilizó dispositivos, como suelas instrumentadas, para medir las presiones ejercidas sobre el suelo durante la marcha o la carrera y la plataforma dinamométrica, considerada la primera plataforma de fuerzas. Por su parte, Muybridge estudió el trote de los caballos y la marcha humana utilizando fotografías seriadas, las cuales quedarían reflejadas en sus obras Locomoción animal en 1877 (Izquierdo, 2008).

La aplicación de la biomecánica al deporte tuvo un origen más reciente con autores como Benedikt (1887) o Braune y Fischer (1895) los cuáles fueron los primeros en realizar un análisis en 3D del movimiento humano calculando velocidades y aceleraciones de los distintos segmentos corporales. Para ello colocaron tubos de luz sobre los segmentos y fotografiaron con cuatro cámaras sincronizadas.

Ya en el siglo XX, Jules Amar (1920) se dedicó al estudio de la mecánica corporal, orientando sus investigaciones al mundo del trabajo. Para realizar sus trabajos diseñó una pista dinamométrica que registraba fuerzas en cuatro direcciones. Su obra The Human Motor se considera como la primera obra dedicada a la Ergonomía. Durante este siglo otros científicos como A.V. Hill (1888-1977), Sir Charles Scott Sherrington (1852-1952) o AF Huxley (1917-2012) los cuáles centraron sus esfuerzos en el estudio de la fisiología muscular (Izquierdo, 2008).

Hasta la mitad de la década de 1960, la tecnología básica utilizada para el registro de los datos fue la cinematografía y la electromiografía. A partir de esta década la llegada de los 
ordenadores, facilitaron el análisis de los datos recogidos por las cámaras y plataformas de fuerzas en los estudios biomecánicos.

Durante la década de 1970 las investigaciones en biomecánica deportiva utilizaban técnicas como la cinematografía, electromiografía, goniometría, plataformas de fuerzas y simulación por computadora.

En España, los orígenes de la biomecánica se localiza en los denominados Institutos Nacionales de Educación Física, Facultades de Medicina, investigadores en ortopedia y cirugía, y la Sociedad Ibérica de Biomecánica y Biomateriales (Viladot, 1992). Esta última nace en 1977 con el objetivo de agrupar a cirujanos, médicos, ingenieros, físicos y especialistas en ciencias de la actividad física y del deporte en un foro para el intercambio de ideas y que al mismo tiempo sirva como estímulo para la investigación.

En 1978 la Universidad Politécnica de Valencia crea un laboratorio de biomecánica que dará origen al actual Instituto de Biomecánica de Valencia (IBV), patentando y comercializando en 1985 su primera plataforma de fuerzas. Puede ser considerada como una de las instituciones más importante en España en el ámbito de la Biomecánica y desarrollos tecnológicos. Actualmente desarrolla y comercializa dispositivos como, Kinescan/I.B.V. Sistema de Análisis de Movimientos; Biofoot/I.B.V. Sistema de plantillas instrumentadas para el análisis de las presiones plantares o Dinascan/I.B.V. - Plataformas dinamométricas, entre otros.

Dentro de las instituciones universitarias españolas y teniendo en cuenta las solicitudes de patentes consultadas, podríamos destacar: Universidad de Valencia, Universidad de Cádiz, Universidad Politécnica de Madrid, Universidad Pablo Olavide de Sevilla, y la Universidad de Granada, entre otras. Dichas instituciones, principalmente por medio de las llamadas Oficinas de transferencia de resultados de la investigación (OTRI), apoyan al personal docente e investigador a la presentación de sus investigaciones, en este caso a modo de patente, para su posible explotación empresarial o venta de derechos.

Desarrollos tecnológicos para la valoración biomecánica de la actividad física y deportiva.

Para Aguado (1993) uno de los objetivos de la biomecánica deportiva es ofrecer nuevos aparatos y metodologías de registro que permitan cuantificar las distintas variables que caracterizan y determinan del movimiento físico. Este desarrollo tecnológico en el campo de la actividad física y del deporte permite mejorar la calidad de las investigaciones, obteniendo mayor información sobre la actividad físico-deportiva mejorando de esta forma el rendimiento físico. Para la realización de estos estudios biomecánicos no es necesario la utilización de instrumentos y dispositivos altamente complejos, sino que, en muchas ocasiones podemos recurrir a sencillas soluciones tecnológicas para dar respuesta a un problema que se nos plantee y cuantificar determinadas variables.

Para estos desarrollos más sencillos o, en ocasiones, basados o apoyados en otros dispositivos ya fabricados, existe en nuestro país un modelo de protección denominado Modelo de Utilidad. Así pues, el Modelo de Utilidad protege invenciones con menor rango inventivo que las protegidas por Patentes, consistentes, por ejemplo, en dar a un objeto una configuración o estructura de la que se derive alguna utilidad o ventaja práctica (O.E.P.M. 2012 c). Entre estos dispositivos, de gran sencillez tecnológica, nos podemos encontrar podómetros y goniómetros modificados, útiles para análisis cinemático (Ferro, 2004), pulsadores plantares (González, 1994 y 1996), etc. 
Los dispositivos e instrumentos de valoración biomecánica sofisticados pueden ser clasificados como cinemáticos directos (electrogoniómetros, acelerómetros, células fotoeléctricas, plataformas de contactos) e indirectos (cinematografía, radiología, fotografía), dinámicos (plataformas de fuerzas y de presiones, calibradores de sujeción, dinamómetros) y otros dispositivos (electromiografía, ergometría y antropometría) (Tabla 1. Aguado, 1993).

Tabla 1. Clasificación de los métodos e instrumentos sofisticados de análisis en biomecánica (Aguado, 1993).

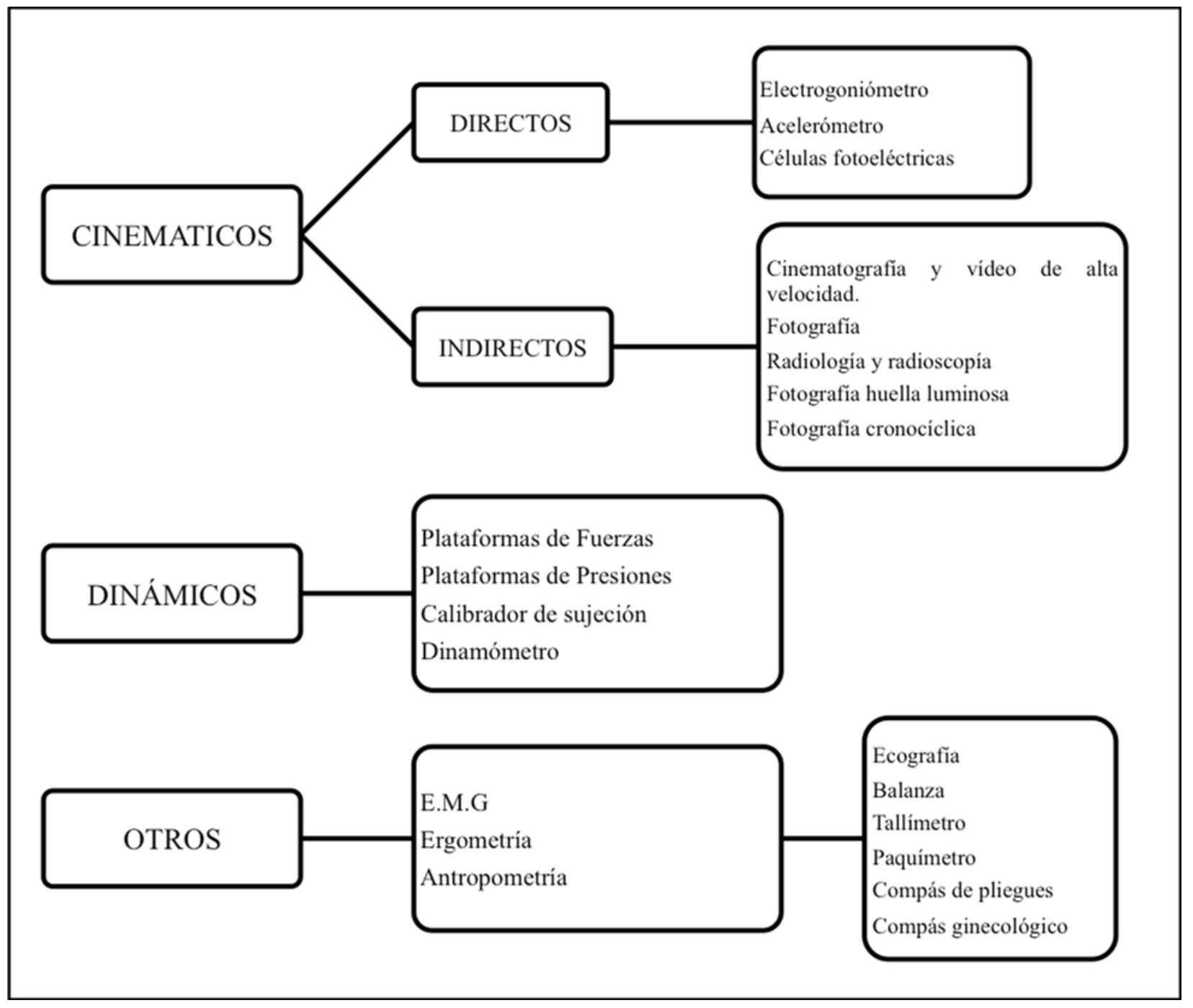

Pérez y Llana (2007), basándose en la distinción entre herramientas de análisis cinemático, cinético o ambas, realizan una revisión de algunos de los dispositivos más utilizados en biomecánica deportiva, diferenciándolos en cronoscopios, fotogrametría y cinematografía, electrogoniometría, dinamografía, electromiografía, acelerometría, electrodinografía, presurometría, modelado y simulación de la técnica deportiva para predecir su ejecución.

\section{Patentes en Biomecánica deportiva}

A continuación se describen en orden cronológico hasta la actualidad, algunos de los instrumentos biomecánicos y de valoración de la actividad física más representativos.

Jump Measuring Device (Kropelnitski, 1974):

Sistema por medio del cual se puede medir la capacidad de salto vertical. Dispone de un dispositivo para indicar el inicio del salto mediante una señal sonora y luminosa. El sujeto, al 
saltar, golpeará con un disco que se desplaza verticalmente por medio de un complemento electromecánico, quedando éste fijado en el punto de la máxima altura alcanzada (Figura 1).

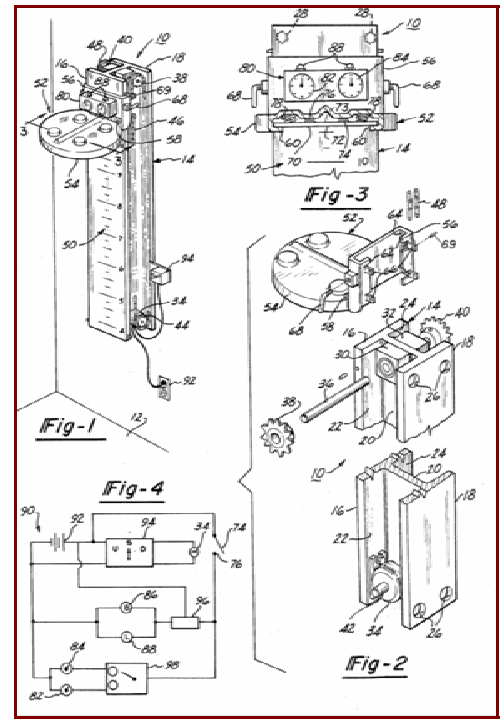

Figura 1. Jump Measuring Device (Kropelnitski, 1974).

\section{Saltómetro Digital (López, 1978):}

Consiste en un dispositivo digital, portátil, con un peso reducido, que permite cuantificar la capacidad de salto vertical. La medición de la altura saltada se calcula mediante la colocación del saltador sobre una plataforma la cual está provista de un interruptor que opera el cronómetro electrónico del saltómetro. A partir del tiempo de vuelo del salto, el instrumento calcula la altura saltada (Figura 2).

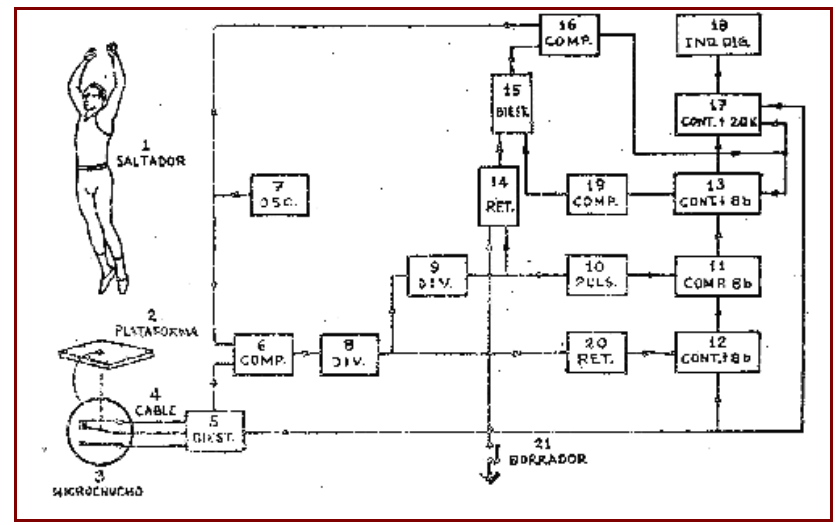

Figura 2. Saltómetro Digital (López, 1978).

Pulsador plantar perfeccionado (González, 1994):

El dispositivo se encuadra dentro de los denominados Modelos de Utilidad. Consiste en un pulsador de pequeño grosor que, colocándose dentro de la zapatilla y a nivel del segundo metatarsiano o en la base del calcáneo, permite la medición de los tiempos de apoyo (y fase aérea). Se caracteriza por estar constituido a partir de dos láminas conductoras conectadas mediante dos terminales a un medidor de tiempos. Entre las láminas metálicas se encuentra situada una lámina de separación realizada en material aislante, y provista de un orificio de 
conexión. Al presionar el pulsador, por medio del apoyo del pie, las láminas conductoras se ponen en contacto y se inicia la medición de tiempo; al finalizar la presión sobre el mismo, finaliza la medición. Su utilidad se encuentra en la medición de tiempos de apoyo y tiempos de vuelo al andar, correr o saltar un deportista (Figura 3).

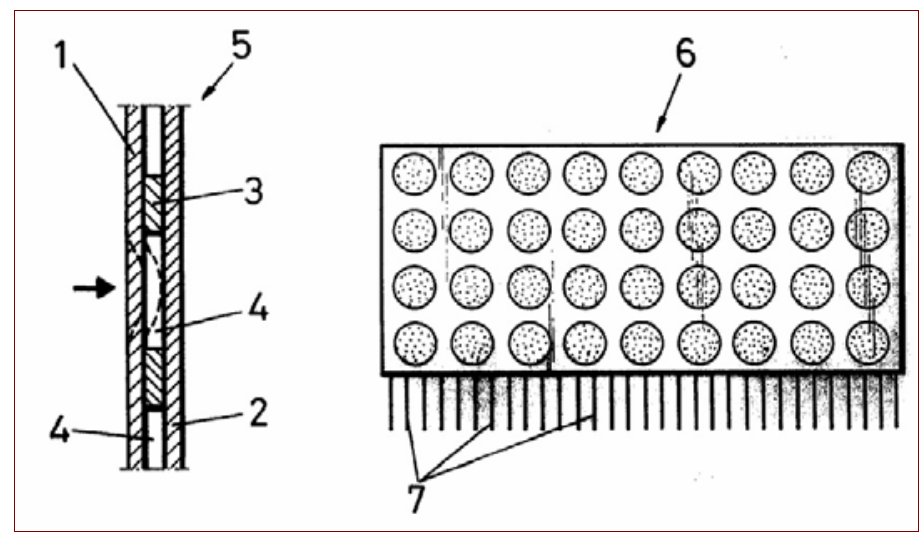

Figura 3. Pulsador plantar perfeccionado (González, 1994).

Raquímetro Extensométrico (Page del Pozo, Vera, Victor, Verde, Moraga, García y Tortosa, 1994):

Dispositivos que permite cuantificar el perfil exterior de la espalda de un sujeto en condiciones dinámicas y estáticas, así como los ángulos de flexión de diferentes segmentos raquídeos en el plano sagital. Posibilita el análisis de la flexión del tronco en distintas condiciones de trabajo, sentados, o incluso cuando éstos apoyan la espalda contra el respaldo de la silla. Se compone de un transductor constituido por un fleje de acero en cuyas caras se posicionan galgas extensométricas, conectadas mediante un cableado que se sitúa paralelamente al fleje y recubriéndose el conjunto por una cubierta de plástico. El cableado se prolonga inferiormente conectándose a un dispositivo electrónico. El raquímetro se fija mediante una faja elástica y bandas elásticas en la zona cervical y lumbar, permitiendo efectuar medidas en tiempo real (Figura 4). 


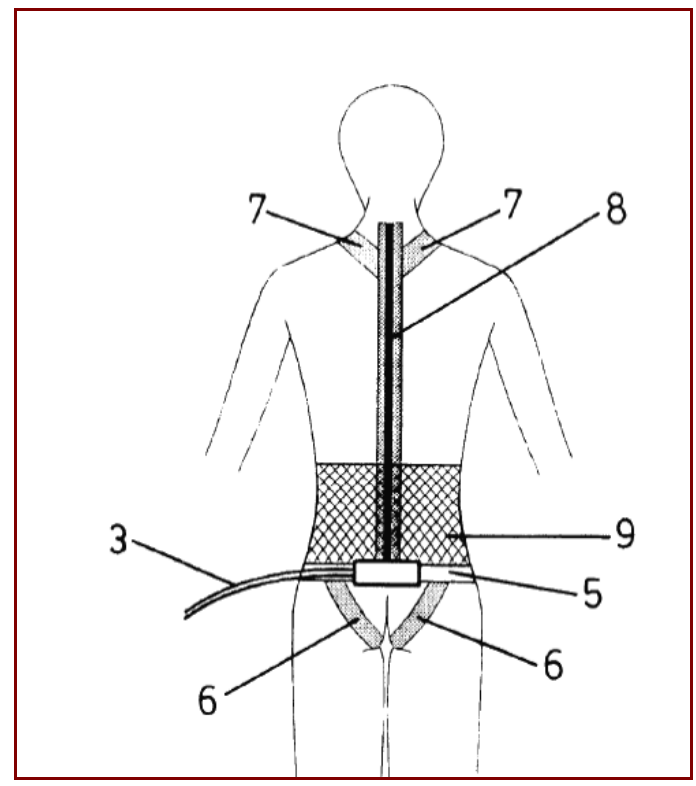

Figura 4. Raquímetro Extensométrico (Page del Pozo y col., 1994).

Podometry system (Soler, Moraga, García, Comin, Llobet y Sánchez, 1995):

Es un sistema que posibilita la medición de registros de la distribución de presiones de la planta del pie del sujeto durante la marcha. Se compone de una plataforma dinamométrica y un podómetro de suelo intercambiable en el que se encuentran dispuestas una serie de cerámicas piezoeléctricas, distribuidas en la superficie para obtener gran resolución. Las señales originadas son tratadas y dirigidas a una tarjeta de adquisición de datos, donde son tratadas y convertidas para su análisis en un ordenador (Figura 5).

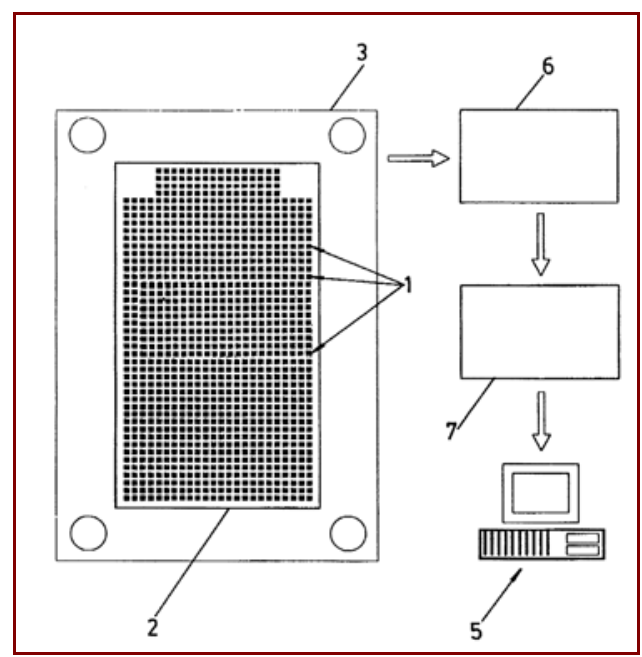

Figura 5. Podometry system (Soler y col., 1995). 
Plantilla instrumentada para la medida de presiones. (Soler, Moraga, García y Miralles, 1995):

Consiste en unas suelas que registran la distribución de las presiones ejercidas por el pie calzado durante la marcha. Las suelas están formadas por una serie de transductores piezoeléctricos colocados en una lámina de caucho y conectados entre sí mediante un circuito eléctrico. La señal es procesada por un grupo de multiplexores los cuales generan una señal analógica que es recogida por una tarjeta de adquisición de datos, amplificando y convirtiendo la señal a digital para su análisis en un ordenador. Dicha tarjeta es transportada por el sujeto en una mochila mientras efectúa la marcha. Como resultado final se obtiene la representación gráfica, en 3 dimensiones, de la distribución de las presiones ejercidas (Figura $6)$.

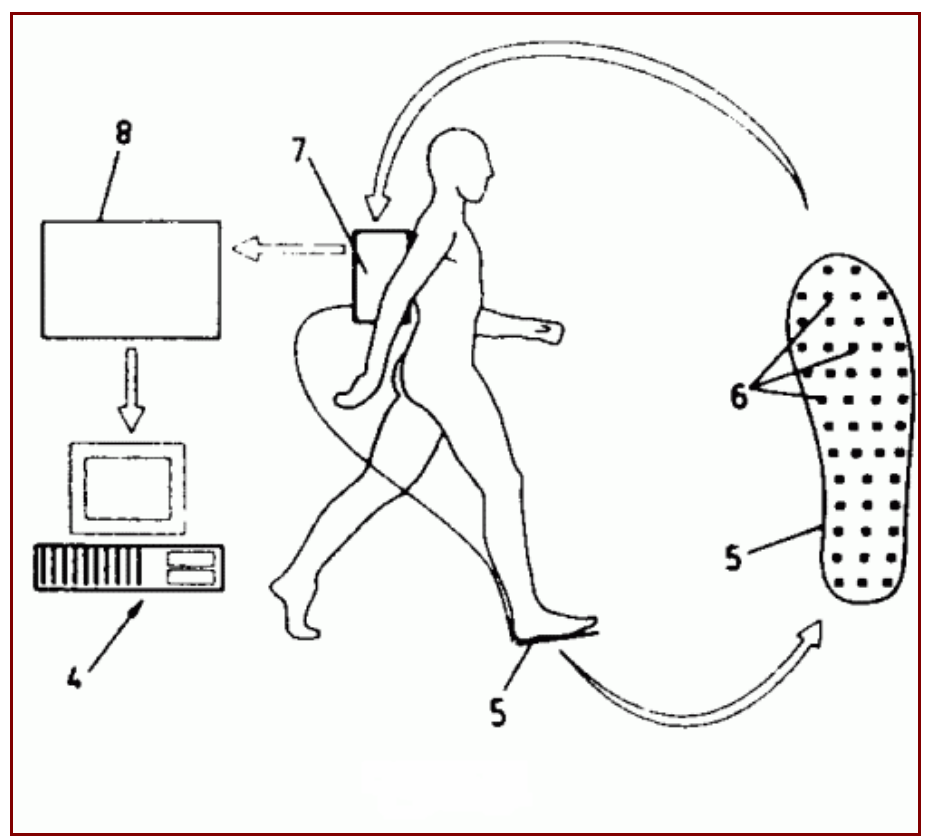

Figura 6. Plantilla instrumentada para la medida de presiones. (Soler y col., 1995).

Performance Measuring Footwear (Kenneth y Anderson, 1995):

Dispositivo utilizado para la medición de parámetros relacionados con la locomoción del ser humano como pueden ser la marcha, la carrera o el salto. Permite medir velocidades y tiempos de vuelo y suelo al realizar cualquier actividad deportiva.

Su estructura consiste en una zapatilla deportiva la cual posee una suela instrumentada con sensores de presión capaces de detectar el momento en el cual la zapatilla deportiva se encuentra en contacto con el suelo o en una fase aérea de cualquier movimiento. Dispone de 4 membranas, que actúan de interruptores, localizadas a la altura del metatarso y otras dos membranas localizadas en el talón. Un microprocesador localizado en el empeine de la zapatilla realiza los cálculos necesarios tras analizar los tiempos de suelo y vuelo del sujeto al realizar actividad física (Figura 7). 


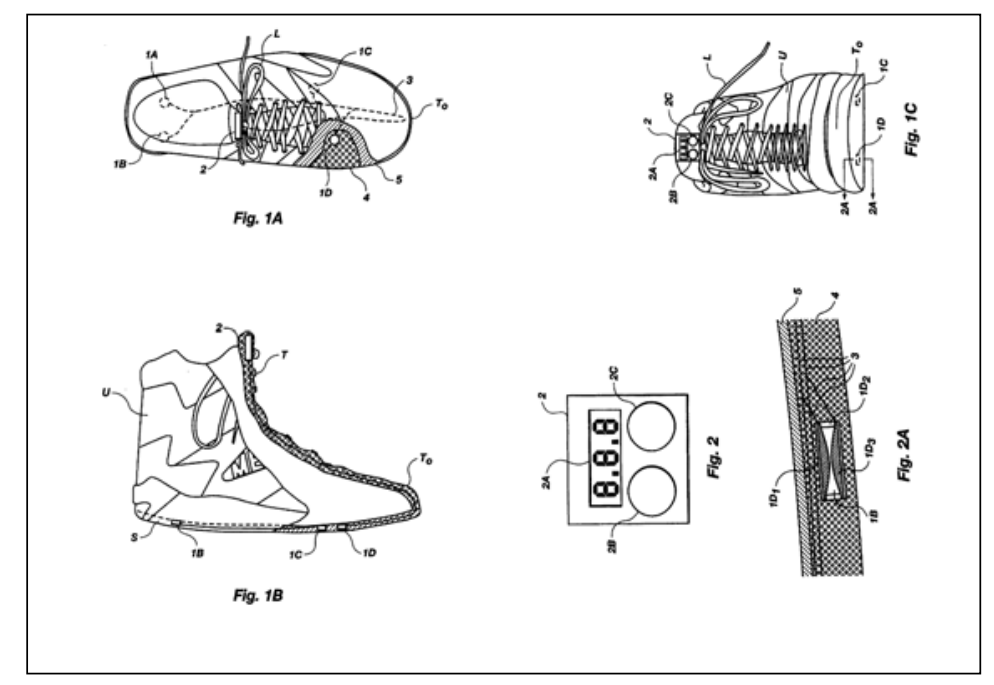

Figura 7. Performance Measuring Footwear (Kenneth y Anderson 1995).

Sistema portátil para el análisis estático y dinámico del apoyo del pie (López, Muñoz, Orrite, Pérez y Santos, 1999):

Dispositivo que permite la medición de presiones provocadas por el apoyo del pie calzado. Utiliza sensores colocados en puntos de interés e integrados en una plantilla de reducido espesor y no alteradora del apoyo. Se compone de un emisor, que transmite las señales de presión mediante un sistema inalámbrico hasta un subsistema receptor, conectado a un ordenador, donde las señales son procesadas y visualizadas. Permite conocer las presiones plantares, en tiempo real, sin limitación de espacio ni limitación de tiempo de registro (Figura 8).

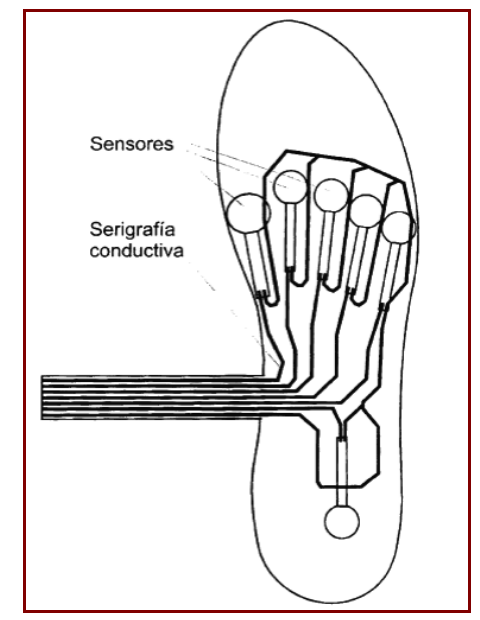

Figura 8. Sistema portátil para el análisis estático y dinámico del apoyo del pie (López y col., 1999).

System and Method for Measuring Movement of Objects (Hutchings, 2000):

Consiste en un dispositivo que mide la distancia recorrida y velocidad alcanzada de un sujeto mientras corre o camina. Además, posibilita cuantificar la altura saltada. Entre los sensores utilizados destacan acelerómetros y sensores de rotación, los cuáles se colocan en la suela del zapato, junto con un circuito electrónico que realiza cálculos matemáticos para determinar las distintas variables. Un transmisor de radio frecuencia envía la información a la unidad central 
de recepción. Un receptor de radio frecuencia, conectado a un microprocesador, calcula la velocidad, basada en el tiempo transcurrido y la distancia recorrida por el corredor (Figura 9).

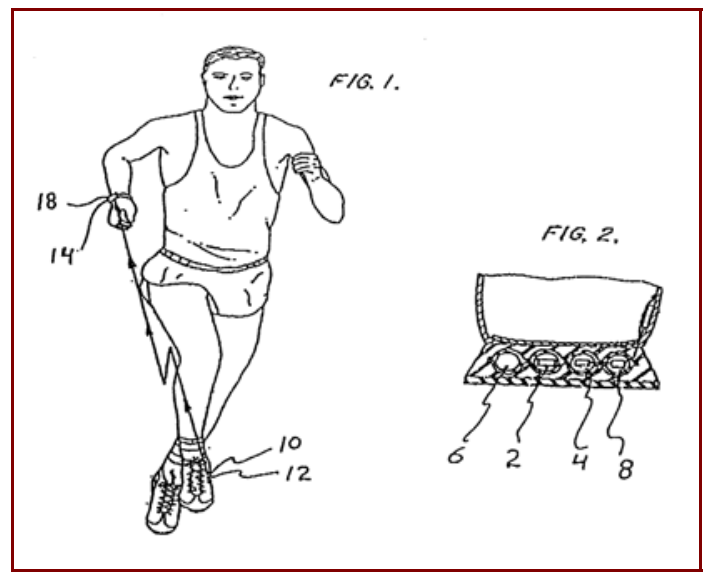

Figura 9. System and Method for Measuring Movement of Objects (Hutchings, 2000).

Vertical Jump Measuring Device (Tipton, Hackworth y Willson, 2001):

Consiste en un dispositivo que utiliza interruptores para cuantificar la capacidad de salto. Parecido al comercializado por Carmelo Bosco en los años 80 con el que comparte ciertas similitudes (Bosco, Luhanen y Komi, 1983). En función del cálculo del tiempo de vuelo y tiempo de contacto con el suelo, el dispositivo permite calcular la altura del salto y el tiempo de impulsión. Consta de una salida a un ordenador en el cual se puede visualizar la marca obtenida (Figura 10).

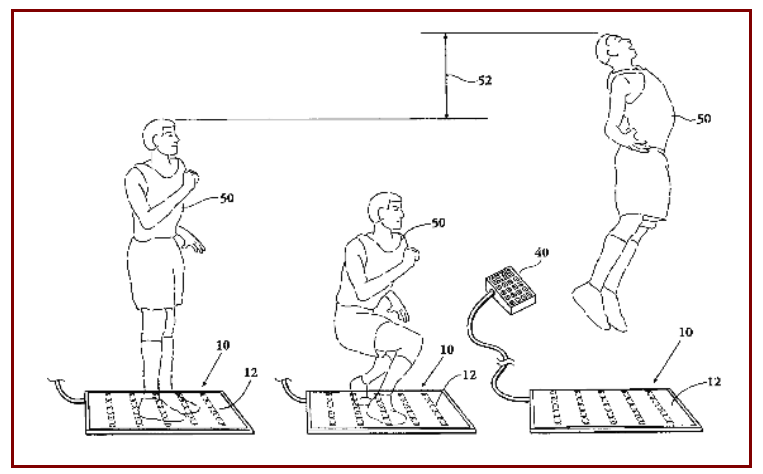

Figura 10. Vertical Jump Measuring Device (Tipton y col., 2001).

Optical height measurement usable for high jump athletes and pole vaulters (Glover M.S. y Glover S.J., 2003):

Permite medir la altura de un salto vertical mediante la utilización de un sistema de emisiónrecepción de luz infrarroja proyectada en forma de haz justo por encima del listón de salto. El dispositivo, apoyado sobre dos soportes verticales, está conectado a un sistema de captura y tratamiento de la señal (Figura 11). 


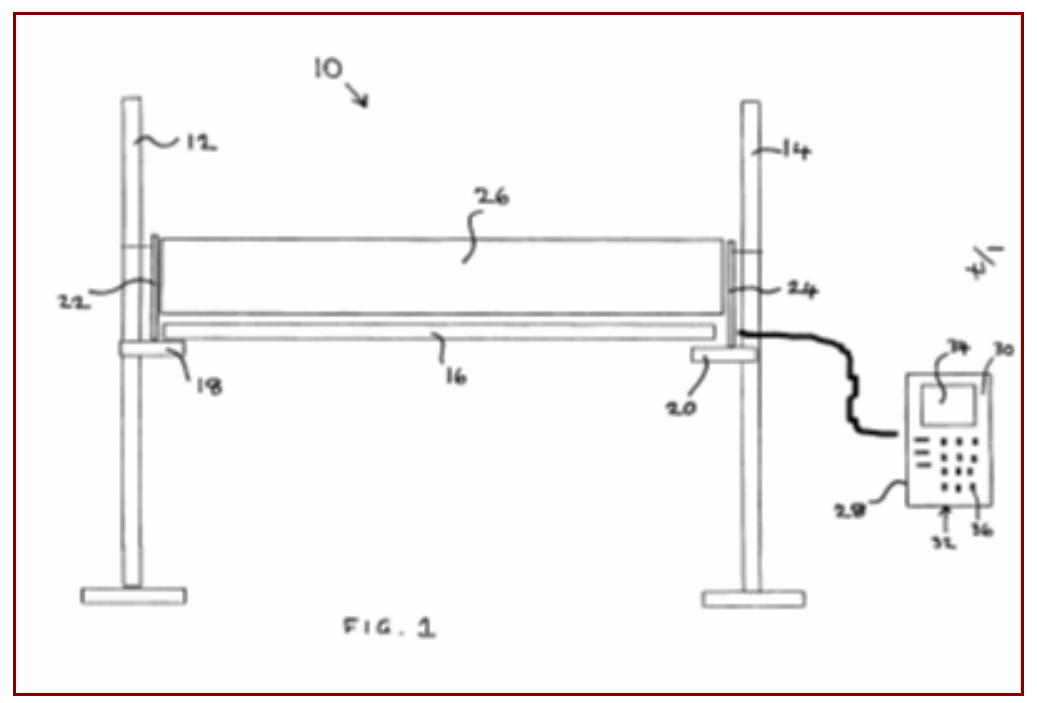

Figura 11. Optical height measurement usable for high jump athletes and pole vaulters (Glover, M.S. y Glover, S.J., 2003).

Caja estanca con mini cámara de video (Ferro, 2004):

La invención, modelo de utilidad, consiste en una caja transparente de metacrilato, cristal o plástico en la que se aloja una mini cámara de vídeo para la filmación de actividades físicas y deportivas. La caja se instala de manera fija y precisa al borde de la piscina mediante una pinza de aluminio acoplada ente el vierteaguas y el vaso, donde se va a realizar la filmación. Está especialmente concebida para el análisis de los movimientos de nadadores o buceadores (Figura 12).

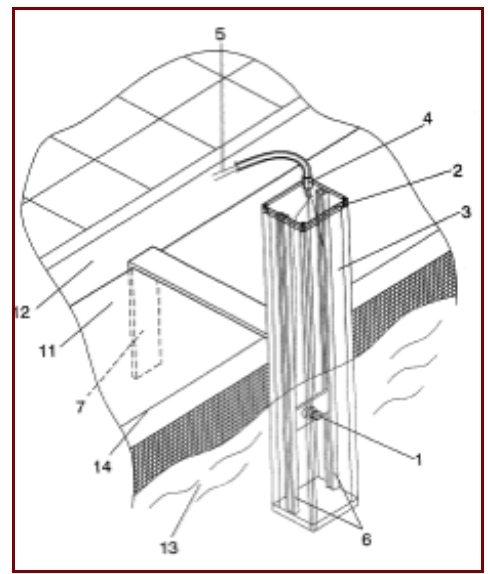

Figura 12. Caja estanca con mini cámara de video (Ferro, 2004). 
Sistema de medición vía ultrasonidos de desplazamientos, y determinación de velocidades y aceleraciones durante la actividad física y deportiva. (González, Guerrero, Mora, Gómez y Quirós, 2004):

Consiste en el desarrollo de un instrumento que utiliza los ultrasonidos para la detección multiposicional de un conjunto de deportistas en un recinto abierto o cerrado con fines de grabar, durante el tiempo de juego, la posición de cada jugador con vistas a un estudio de las consecuencias de sus distintas intervenciones. El mecanismo se basa en el envío de pulsos de ultrasonidos secuenciales desde distintos puntos fijos del recinto de juego. La determinación del tiempo necesario en cubrir los trayectos entre esos distintos emisores fijos y la posición instantánea del deportista permitirá conocer las distancias equivalentes desde cada foco hasta el receptor, a partir del conocimiento de la velocidad de propagación acústica en el medio. Mediante cálculos trigonométricos será posible la localización espacial del equipo receptor de ultrasonidos (Figura 13).

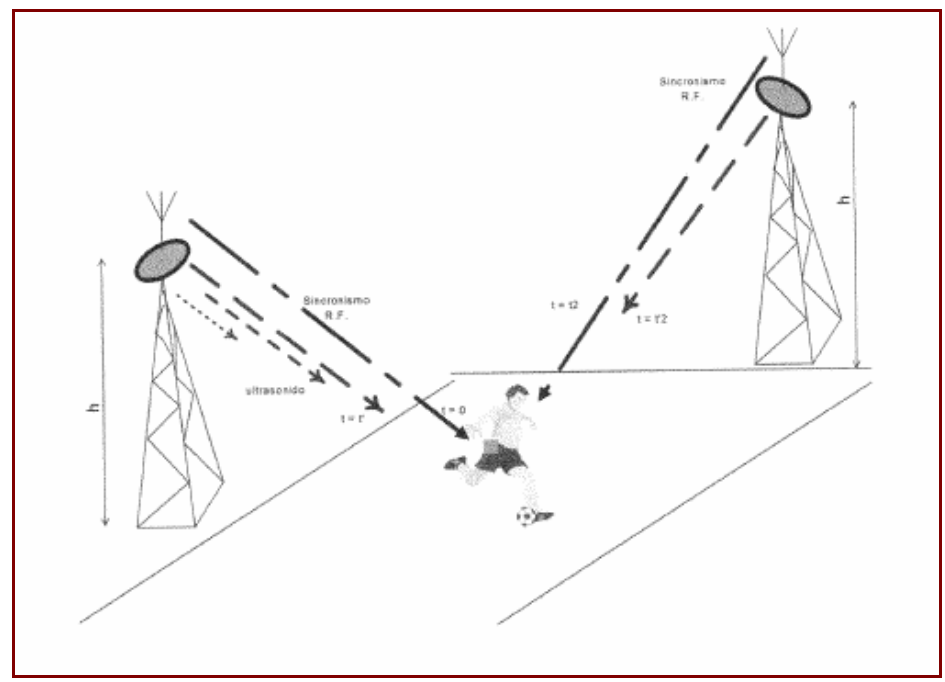

Figura 13. Sistema de medición vía ultrasonidos de desplazamientos, y determinación de velocidades y aceleraciones durante la actividad física y deportiva (González y col., 2004).

Sistema telemétrico de cronometraje con fotocélulas láser (Morante, Paz, García y Redondo, 2005):

La presente invención se refiere a un sistema telemétrico de cronometraje con fotocélulas láser cuya finalidad es proporcionar la medición de tiempos de actividades deportivas. El sistema de la invención consta de unos emisores de luz láser que se proyectan sobre unos receptores fotosensibles. Cada pareja de emisor y receptor láser se sitúan enfrentados formando una barrera que permite detectar el paso de un deportista o de un objeto (balón, pelota, bicicleta, vehículo, etc.) a través de ella, cuando se origina un corte en la llegada del haz láser al receptor fotosensible, tomándose esa referencia temporal como inicio o finalización del cronometraje (Figura 14). 


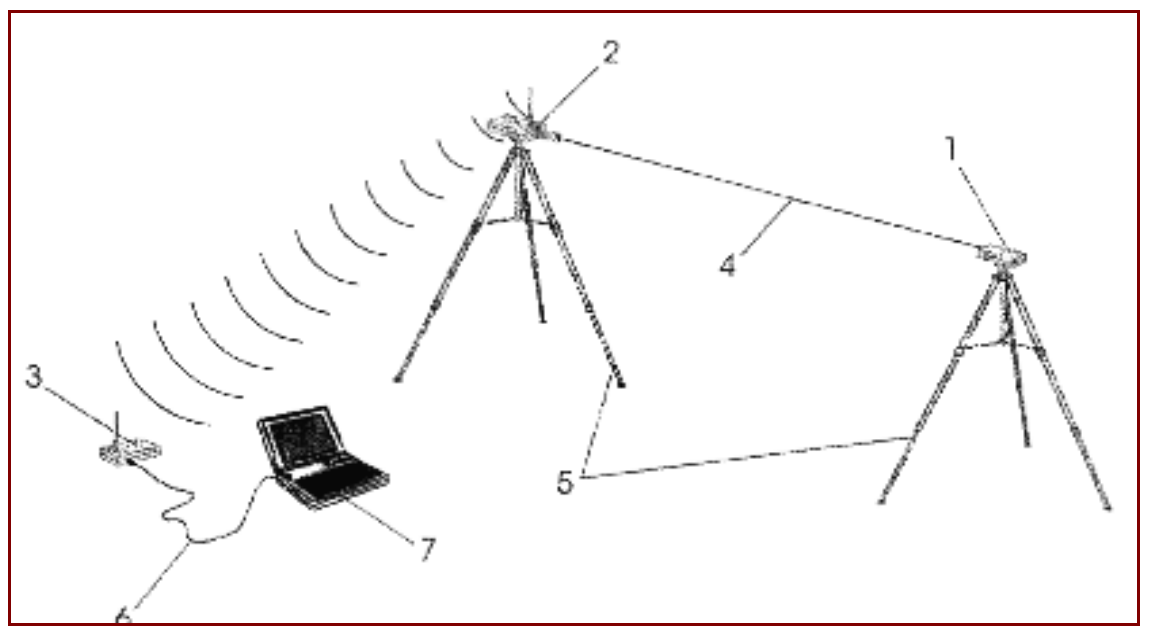

Figura 14. Sistema telemétrico de cronometraje con fotocélulas láser (Morante y col., 2005).

IR System for kinematic analysis (Alan, 2007).

Este sistema comprende la colocación de marcadores en el deportista los cuales transmiten, mediante señal infrarroja, la posición de cada uno de los segmentos corporales. En la descripción del aparato el autor lo orienta hacia su utilización en el golf, permitiendo correlacionar el movimiento realizado por el golfista con la trayectoria descrita por la bola. Su mayor ventaja es que permite el análisis cinemático minimizando las restricciones del movimiento debido al aparataje (Figura 15).

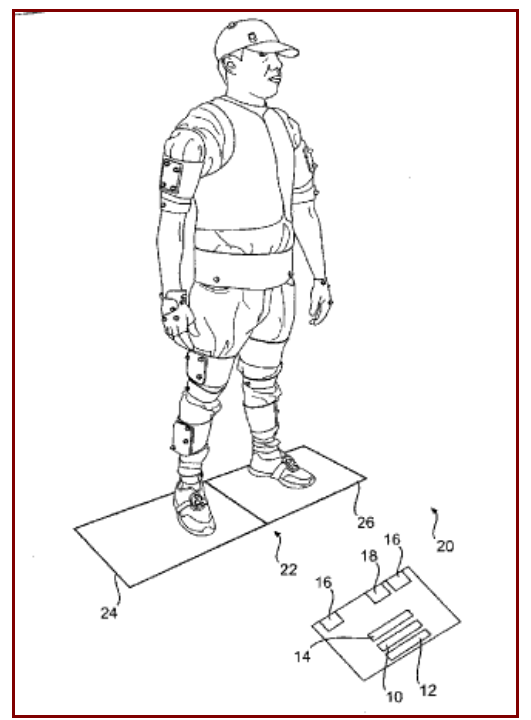

Figura 15. IR System for kinematic analysis (Alan, 2007). 
Sistema de monitorización del movimiento (Izquierdo, Llarrión y Santamaría, 2007):

Los autores proponen un sistema portátil para la medición y análisis, en condiciones estandarizadas, de la velocidad, potencia muscular y estabilidad del movimiento. El sistema consta de un módulo sensor, destinado para la obtención de variables cinemáticas del individuo analizado, como velocidad de desplazamiento, aceleración, posición y giro; transmitiéndose la información mediante un sistema de radiofrecuencia a un equipo informático receptor, el cual procesa dicha información. El módulo sensor, que obtiene magnitudes físicas consta de tres giróscopos, tres acelerómetros y tres magnetómetros, de forma que cada eje del espacio es analizado independientemente (Figura 16).

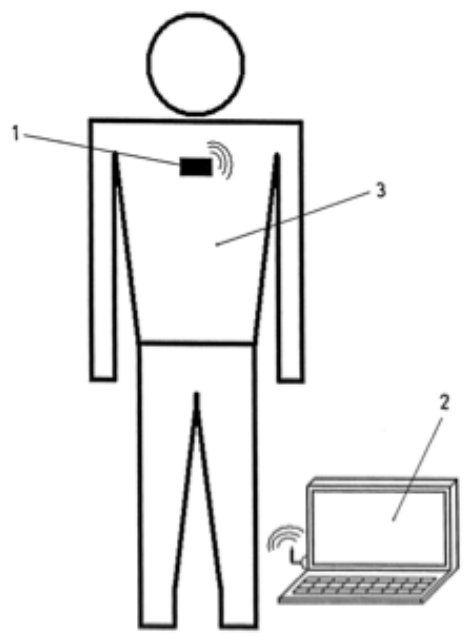

Figura 16. Sistema de monitorización del movimiento (Izquierdo y col., 2007).

Multi-sensor monitoring of the athletic performance (Case, Charles y Martin (2007):

El sistema "Multi-sensor monitoring of the athletic performance" es descrito como un instrumento portátil para la monitorización de parámetros fisiológicos y cinemáticos, permitiendo además la conexión de dispositivos multimedia de audio y vídeo. Entre las posibilidades de medición, se encuentra la monitorización de variables fisiológicas (frecuencia cardiaca, presión arterial y temperatura corporal) y variables cinemáticas (distancia, velocidad, aceleración y altura). Además incorpora un dispositivo de posicionamiento global G.P.S., para la localización espacial del deportista (Figura 17). 


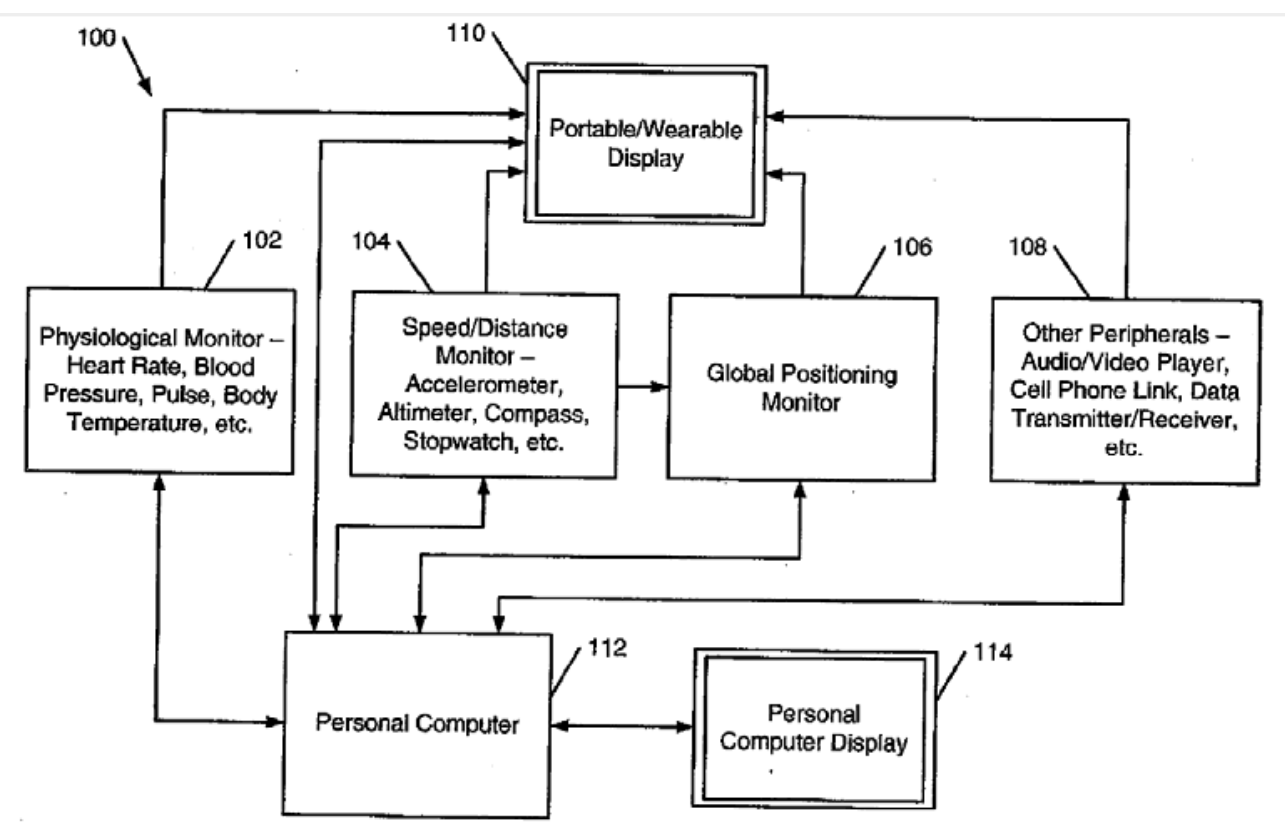

Figura 17. Multi-sensor monitoring of the athletic performance (Case y col., 2007).

Sistema de análisis cinemático en tiempo real (Ferro y Floria, 2010):

El Sistema de análisis cinemático en tiempo real para entrenamientos y competiciones deportivas, está compuesto por un cabezal láser para el registro de datos, conectado a un sistema informático que los procesa y un soporte para el cabezal láser. La estructura donde se sitúa el dispositivo laser está compuesto por una base de apoyo, un raíl vertical y un raíl horizontal, sobre los cuales se desplaza simultáneamente permitiendo el seguimiento contínuo del deportista. Su principal ventaja, sobre otras tecnologías, es que no interfiere sobre la técnica del deportista ya que éste no debe ocuparse en participar en la medición, no requiere una calibración del espacio y los resultados se obtienen en tiempo real, por lo que es muy útil para facilitar feedback inmediato al deportista (Figura 18).

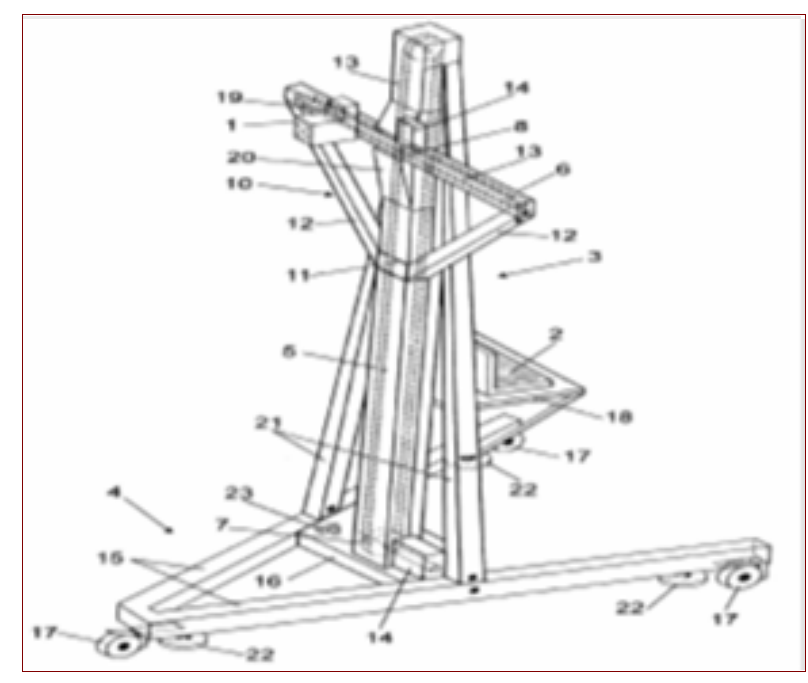

Figura 18. Dispositivo de análisis de variables cinemáticas para la carrera mediante laser. (Ferro y Floria, 2010). 
Sistema de medición de parámetros temporales de la marcha, la carrera y el salto mediante fotodetectores (González, Palma, Carvajal, Ruiz, Mora, y Martínez, 2008):

Esta invención se refiere a un instrumento de detección y medida de apoyos durante la marcha, saltos y carreras, basado en el uso de elementos fotodetectores para discriminar los apoyos. El dispositivo cuenta con un módulo hardware principal que se coloca sobre el cuerpo del sujeto bajo estudio, y es una unidad física compuesto por un módulo de alimentación, un módulo para comunicación inalámbrica, módulo de acondicionamiento de las señales procedentes de los fotodetectores y una memoria de datos de alta capacidad para servir de almacenamiento intermedio hasta la comunicación con el ordenador. El funcionamiento se basa en el registro de los cambios en las señales procedentes de los fotodetectores, incluidos en las suelas. Al apoyar y levantar la suela, el nivel de luz procedente de la reflexión con el suelo o por incidencia directa varía en el fotodetector, modificándose su salida. Esta modificación constituye el cambio que se procesa para señalar la dinámica del pie, bien sea andando, corriendo o saltando (Figura 19).

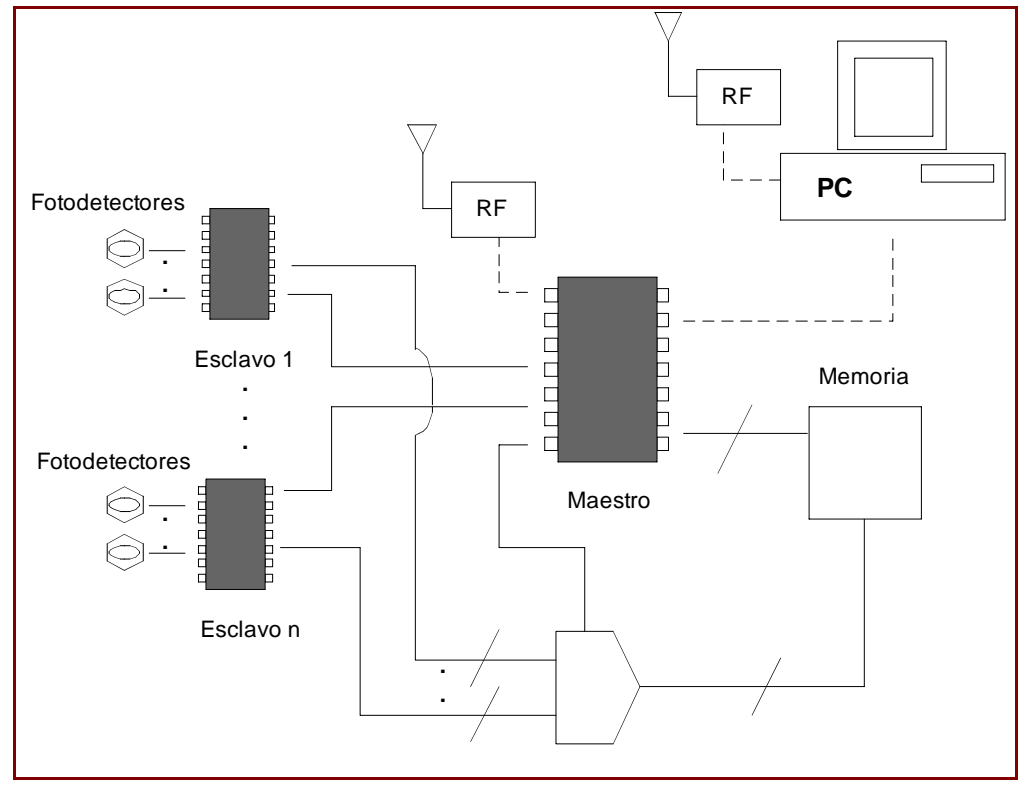

Figura 19. Diagrama del Sistema de medición de parámetros temporales de la marcha, la carrera y el salto mediante fotodetectores (González y col., 2008).

Monitoring sports (Grenfell, Zhang, Mackintosh, James y Davey (2010):

Consiste en un registrador de datos compuesto por un acelerómetro, unidad GPS, monitor de la frecuencia cardíaca y un software para tratamiento de los datos. Los datos pueden ser almacenados o transmitidos a un ordenador para su uso por el entrenador. Los inventores consideran el dispositivo como útil para deportes como fútbol, atletismo, ciclismo y deportes de invierno (Figura 20). 


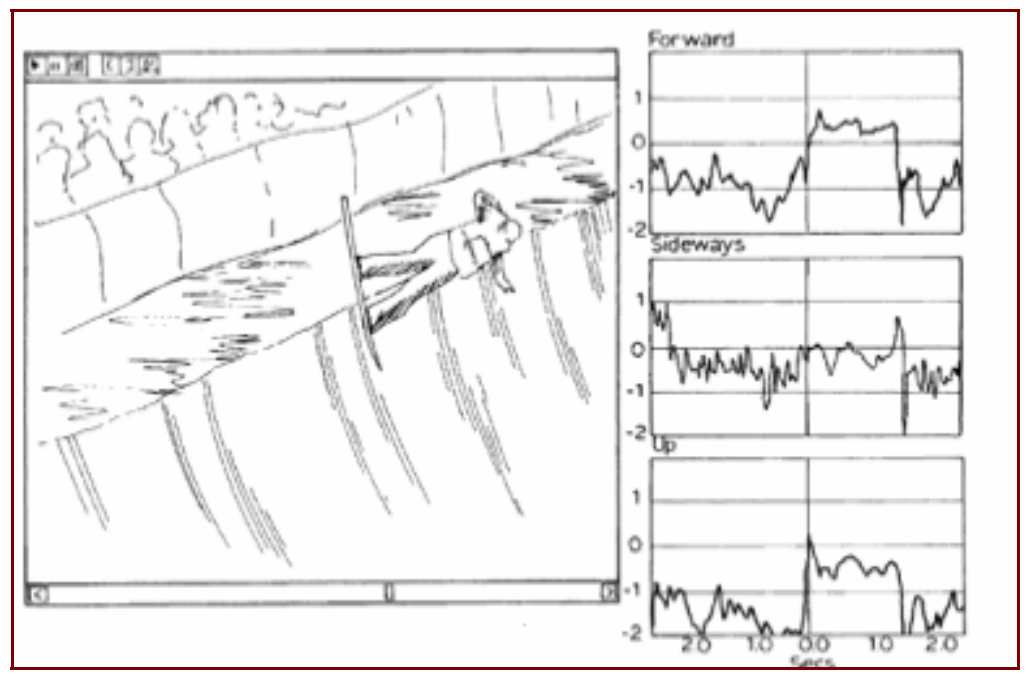

Figura 20. Monitoring sports (Grenfell y col., 2010).

Motion analysis device for sports (Irlam, J.C. y Irlam, L.J., 2010):

Consiste en un dispositivo formado por un compartimento estanco en la cual se encuentra, en su interior, un acelerómetro triaxial que proporciona información sobre los movimientos realizados por el deportista. Este dispositivo se coloca a modo de reloj en la muñeca del deportista proporcionando la señal de la aceleración realizada en los 3 ejes del movimiento (Figura 21).

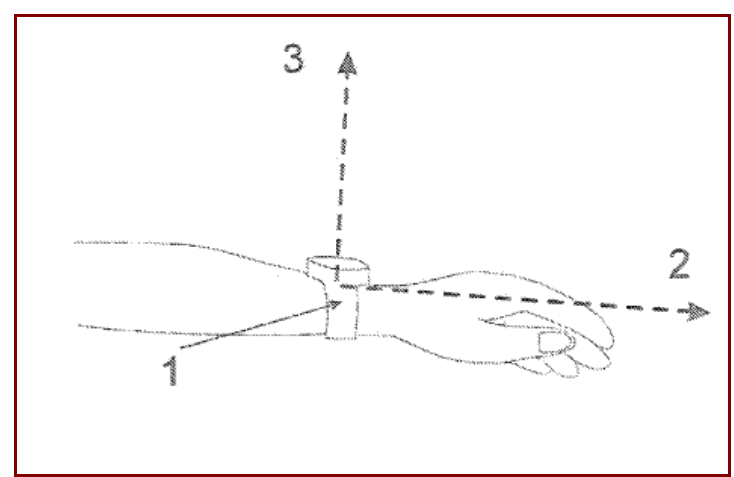

Figura 21. Motion analysis device for sports, (Irlam, J.C., y Irlam L.J., 2010).

Athletic performance monitoring systems and methods in a team sports environment (Molyneux, Weast y Burroughs, 2010):

Consiste en un conjunto de sensores los cuales se colocan en las zapatillas del deportista para detectar y monitorizar varios parámetros cinemáticos relacionados con el rendimiento deportivo durante el transcurso de un partido o de una sesión de entrenamiento en deportes como fútbol, hockey, baloncesto o rugby. Los sensores utilizados son acelerómetros triaxiales, los cuáles envía la información, vía inalámbrica, a una unidad central. El sistema permite monitorizar además los desplazamientos del balón. Este sistema está basado en el NIKE+TM sistema para monitorizar del rendimiento deportivo patentado por NIKE Inc. (Figura 22). 


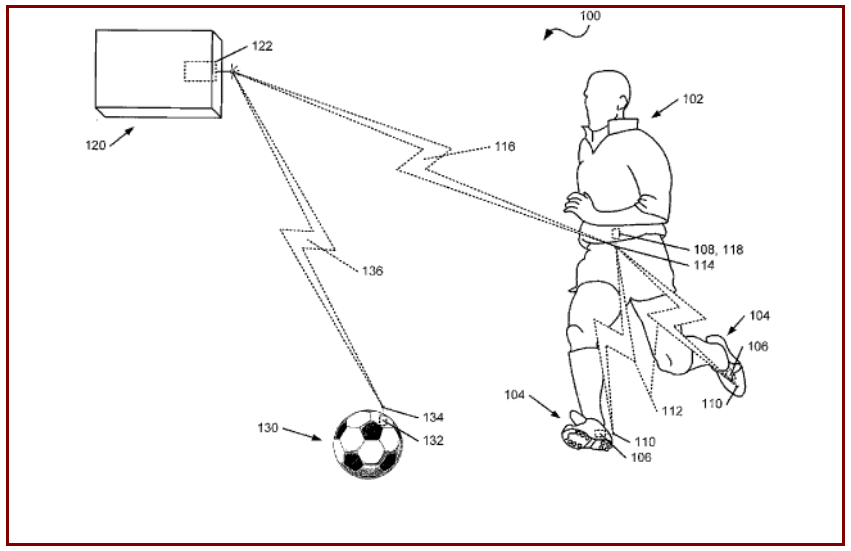

Figura 22. Athletic performance monitoring systems and methods in a team sports environment (Molyneux y col., 2010).

Sistema portátil de valoración de la capacidad de salto vertical (González y Ruiz, 2010):

Esta invención, consiste en un dispositivo que permite la medición de la capacidad de salto vertical mediante la utilización de la capacidad de conducción eléctrica. Comprende componentes de instrumentación o hardware, un componente lógico de programación, un conjunto de elementos de detección metálicos y una plataforma conductora sobre la cual el sujeto realiza el salto. El módulo hardware principal, es una unidad física que se conecta mediante cable o de forma inalámbrica a una abrazadera colocada en el pie del sujeto. Para el tratamiento de los pulsos generados por el sujeto al saltar se utiliza uno o dos microprocesadores, en función del número de sensores acoplados al sistema. Uno de ellos gestiona el acceso al buffer de datos y otro proporciona la gestión del reloj interno encargado de la medición de tiempos.

El detector de suela, en el cual se localizan los elementos de detección, se coloca en el pie del deportista, y es el encargado de detectar cuando el sujeto esta en el suelo o en el aire. Estos contactos hacen que al apoyar el pie sobre una superficie conductora, se cierre el circuito eléctrico y se transmita dicho evento al microprocesador (Figura 23).

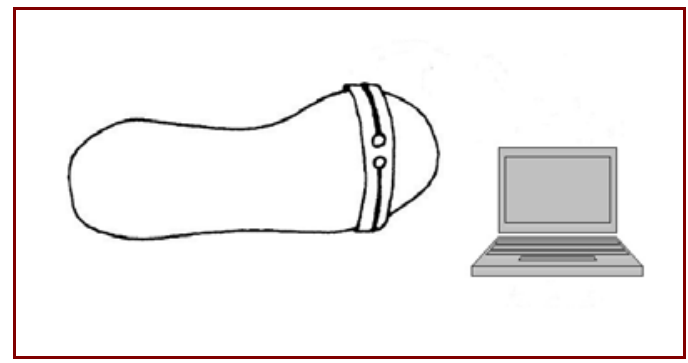

Figura 23. Sistema de valoración de la capacidad de salto vertical (González y Ruiz, 2010). 
Sistema de indicación y supervisión en tiempo real de la corrección postural de la columna vertebral y aplicaciones que requieran análisis cinemático o dinámico (Fernández, López y Ruiz, 2011):

El dispositivo consiste en un instrumento electrónico, autónomo e inalámbrico cuyo objetivo es la corrección postural de la columna vertebral y el análisis de movimientos deportivos. Para ello, realiza un análisis, control, registro y monitorización de diferentes variables cinemáticas y/o dinámicas. El dispositivo está formado por acelerómetros, giroscopios y compases para calcular la dirección del movimiento, todos ellos triaxiales, así como un sensor para la medición de la temperatura corporal. El sistema incluye un módulo de control y de procesamiento de la señal formado por dispositivos tipo ordenador PC, PDA, etc. (Figura 24).

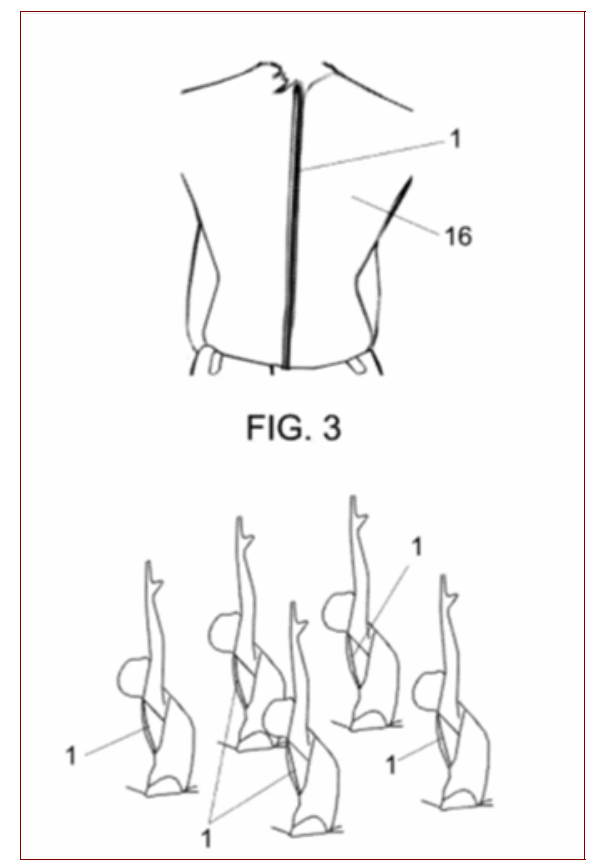

Figura 24. Sistema de indicación y supervisión en tiempo real de la corrección postural de la columna vertebral (Fernández y col., 2011).

Sports training analyzing system based on digital field and high-speed image. (Yu, Yining, Shengnian y Xianjun, 2011):

Sistema de análisis del movimiento deportivo basado en un campo digital y en el análisis de imágenes obtenidas mediante cámaras de alta velocidad. El campo de actividad digital está compuesto por diferentes módulos conectados entre si y dispuestos en el centro la pista, donde se va a realizar la actividad, mientras que el sistema de cámaras de alta velocidad está formado por un grupo de 8 cámaras distribuidas de forma que cubren todo el campo de actividad digital. Todos los dispositivos se encuentran sincronizados entre si mediante un controlador y conectados a un equipo para transferir e interpretar los datos (Figura 25). 


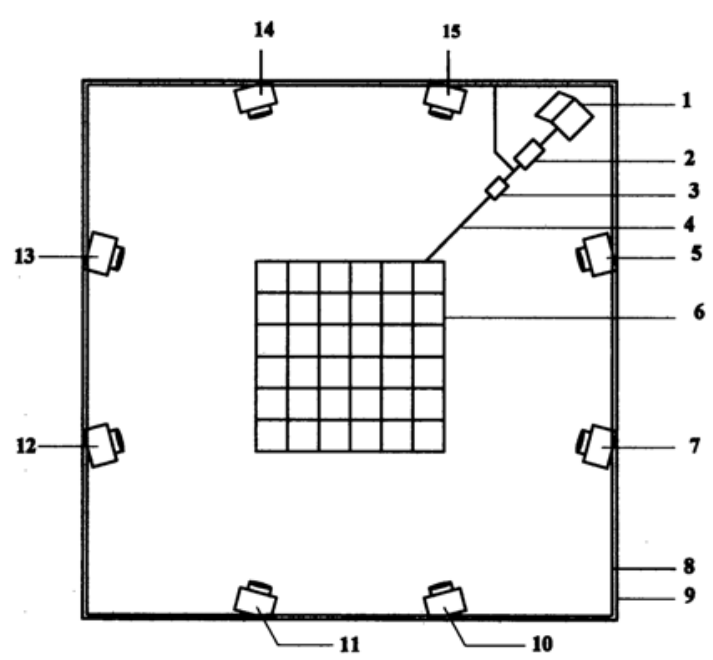

Figura 25. Sports training analyzing system based on digital field and high-speed image. (Yu y col., 2011)

System and methods for real-time physiological monitoring (Adidas, 2012):

Este dispositivo monitoriza, en tiempo real y de forma inalámbrica, variables fisiológicas como la frecuencia cardiaca, frecuencia respiratoria y temperatura corporal e incorpora un dispositivo para el análisis de la actividad física y análisis postural mediante sensores de posición y acelerometría incorporados en un chaleco transportado por el sujeto (Figura 26).

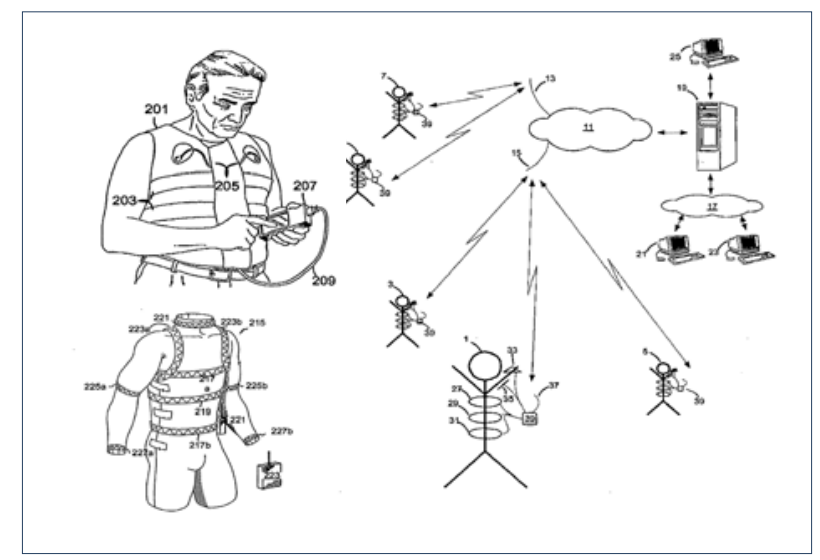

Figura 26. System and methods for real-time physiological monitoring (Adidas, 2012).

Tras la revisión realizada, resumida en la Tabla 2, se observa que existen diversos dispositivos registrados por investigadores, instituciones y centros de investigación. Es imprescindible el registro de los dispositivos e instrumentos desarrollados, no solo como medida de protección ante posibles copias sino además hacia la búsqueda de una posible explotación comercial o cesión de derechos que, al menos, compense el esfuerzo económico invertido en su desarrollo tanto por las instituciones públicas como privadas.

El proceso de innovación no está limitada a grandes centros de investigación deportiva como son las distintas universidades o los centros de alto rendimiento sino que está abierto a todos aquellos investigadores que, aunque no estén integrados dentro de dichos centros de 
investigación, posean capacidad inventiva que permita resolver problemas o deficiencias instrumentales mediante el desarrollo de dispositivos innovadores. Así por ejemplo, algunas de las patentes reflejadas en el presente artículo han sido solicitadas por los propios autores (González 1994, Fernández y col., 2011) y solo aquellos autores que en la fecha de la solicitud se encuentren dentro de una institución, pública o privada, desempeñando un cargo como personal docente, investigador, etc., tiene el deber de poner a disposición de su institución responsable los resultados, en forma de patentes, de sus distintas investigaciones. Es por esta razón por lo que autor/a y solicitante/s no tienen por qué coincidir.

Tabla 2. Tabla resumen de las patentes relacionadas con la biomecánica deportiva en función de su utilidad y tecnología utilizada.

\begin{tabular}{|c|c|c|c|}
\hline AUTOR & PATENTE & REIVINDICACIÓN & TECNOLOGÍA \\
\hline Kropelnitski, (1974). & $\begin{array}{l}\text { Jump Measuring Device. } \\
\text { Patente nacional. }\end{array}$ & $\begin{array}{l}\text { Capacidad de salto } \\
\text { vertical. }\end{array}$ & $\begin{array}{l}\text { Sensor } \\
\text { electromecánico. }\end{array}$ \\
\hline López, (1978). & $\begin{array}{l}\text { Saltómetro Digital. } \\
\text { Patente nacional. } \\
\text { Solicitante: Inst. Nac. } \\
\text { Deporte Educación. }\end{array}$ & $\begin{array}{l}\text { Capacidad de salto } \\
\text { vertical. }\end{array}$ & Sensor electrónico. \\
\hline González, (1994). & $\begin{array}{l}\text { Pulsador Plantar } \\
\text { Perfeccionado. } \\
\text { Modelo Utilidad. } \\
\text { Solocitante: Autor. }\end{array}$ & $\begin{array}{l}\text { Capacidad de salto } \\
\text { vertical. }\end{array}$ & Sensor mecánico. \\
\hline Page del Pozo y col., (1994). & $\begin{array}{l}\text { Raquímetro extensométrico. } \\
\text { Patente nacional. } \\
\text { Solicitante: Universidad } \\
\text { Politécnica de Valencia. IBV. }\end{array}$ & $\begin{array}{l}\text { Ángulos de flexión } \\
\text { segmentos raquídeos. }\end{array}$ & $\begin{array}{l}\text { Sensor transductor: } \\
\text { Fleje de } \\
\text { acero y galgas } \\
\text { extensométricas. }\end{array}$ \\
\hline Soler y col., (1995). & $\begin{array}{l}\text { Plantilla instrumentada. } \\
\text { Patente nacional. } \\
\text { Solicitante: Meditel } \\
\text { Ingeniería Técnica. }\end{array}$ & $\begin{array}{l}\text { Registro de } \\
\text { presiones. }\end{array}$ & $\begin{array}{l}\text { Sensores de } \\
\text { presión. }\end{array}$ \\
\hline Kenneth y Anderson, (1995). & $\begin{array}{l}\text { Performance Measuring } \\
\text { Footwear. } \\
\text { Patente nacional. }\end{array}$ & $\begin{array}{l}\text { Registro de } \\
\text { presiones. }\end{array}$ & $\begin{array}{l}\text { Sensores de } \\
\text { presión. }\end{array}$ \\
\hline López y col., (1999). & $\begin{array}{l}\text { Sistema para el análisis } \\
\text { estático y dinámico del apoyo } \\
\text { del pie. } \\
\text { Patente nacional. } \\
\text { Meditel Ingeniería Médica. }\end{array}$ & $\begin{array}{l}\text { Registro de } \\
\text { presiones. }\end{array}$ & $\begin{array}{l}\text { Sensores de } \\
\text { presión. }\end{array}$ \\
\hline Hutchings, (2000). & $\begin{array}{l}\text { System and Method for } \\
\text { Measuring Movement of } \\
\text { Objects. } \\
\text { Patente nacional. } \\
\text { Solicitante: Aceleron } \\
\text { Technologies }\end{array}$ & $\begin{array}{l}\text { Cálculo distancia } \\
\text { recorrida, velocidad y } \\
\text { altura del salto. }\end{array}$ & $\begin{array}{l}\text { Acelerómetros y } \\
\text { sensores de } \\
\text { rotación. }\end{array}$ \\
\hline Tipton y col., (2001). & $\begin{array}{l}\text { Vertical Jump Measuring } \\
\text { Device. } \\
\text { Patente nacional. } \\
\text { Solicitante: Universidad de } \\
\text { Tulsa }\end{array}$ & $\begin{array}{l}\text { Medición altura salto } \\
\text { vertical. }\end{array}$ & Interruptores. \\
\hline $\begin{array}{l}\text { M.S. Glover y S.J. Glover, } \\
\text { (2003). }\end{array}$ & $\begin{array}{l}\text { Optical height measurement } \\
\text { usable for high jump athletes } \\
\text { and pole vaulters. } \\
\text { Patente nacional. }\end{array}$ & $\begin{array}{l}\text { Cálculo salto de } \\
\text { altura. }\end{array}$ & $\begin{array}{l}\text { Sensores } \\
\text { infrarrojos. }\end{array}$ \\
\hline Ferro, (2004). & $\begin{array}{l}\text { Caja estanca con cámara de } \\
\text { video. } \\
\text { Modelo de utilidad. }\end{array}$ & $\begin{array}{l}\text { Análisis de los } \\
\text { movimientos de } \\
\text { nadadores. }\end{array}$ & Sensor video. \\
\hline
\end{tabular}


González-Montesinos, J. L.; Fernández-Santos, J. R. (2012). Origen y evolución de las patentes y marcas en biomecánica deportiva. RICYDE. Rev. int. cienc. deporte. 30(8), 276-304. http://dx.doi.org/10.5232/ricyde2012.03001

\begin{tabular}{|c|c|c|c|}
\hline González y col., (2004). & $\begin{array}{l}\text { Sistema de medición vía } \\
\text { ultrasonidos. } \\
\text { Patente nacional. } \\
\text { Solicitante: Universidad de } \\
\text { Cádiz. }\end{array}$ & Análisis cinemático. & Sensor ultrasonidos. \\
\hline Morante y col., (2005). & $\begin{array}{l}\text { Sistema de cronometraje con } \\
\text { fotocélulas láser. } \\
\text { Patente nacional. } \\
\text { Solicitante: Desarrollo de } \\
\text { Software Deportivo. }\end{array}$ & Medición tiempos. & Sensor laser. \\
\hline Alan, (2007). & $\begin{array}{l}\text { IR System for kinematic } \\
\text { analysis. } \\
\text { Patente nacional. }\end{array}$ & Análisis cinemático & Sensor infrarrojo. \\
\hline Izquierdo y col., (2007). & $\begin{array}{l}\text { Sistema de monitorización } \\
\text { del movimiento del ser } \\
\text { humano. } \\
\text { Patente nacional. }\end{array}$ & $\begin{array}{l}\text { Velocidad, potencia } \\
\text { muscular y } \\
\text { estabilidad. }\end{array}$ & $\begin{array}{l}\text { Sensores } \\
\text { giróscopos, } \\
\text { acelerómetros. }\end{array}$ \\
\hline Case y col., (2007). & $\begin{array}{l}\text { Multi-sensor monitoring of } \\
\text { the athletic performance. } \\
\text { Patente internacional. } \\
\text { Solicitante: Nike Inc. }\end{array}$ & $\begin{array}{l}\text { Variables fisiológicas } \\
\text { y análisis cinemático }\end{array}$ & $\begin{array}{l}\text { Pulsómetro, } \\
\text { termómetro, } \\
\text { tensiómetro, } \\
\text { acelerómetro y } \\
\text { GPS. }\end{array}$ \\
\hline Ferro y Floria, (2010). & $\begin{array}{l}\text { Sistema de análisis } \\
\text { cinemático para } \\
\text { entrenamientos y } \\
\text { competiciones deportivas. } \\
\text { Patente nacional. } \\
\text { Solicitante: Universidad } \\
\text { Politécnica de Madrid y } \\
\text { Universidad Pablo Olavide } \\
\text { Sevilla. }\end{array}$ & Análisis cinemático. & Sensor laser. \\
\hline González y col., (2010). & $\begin{array}{l}\text { Sistema de medición de } \\
\text { parámetros temporales de la } \\
\text { marcha, la carrera y el salto } \\
\text { mediante fotodetectores. } \\
\text { Patente internacional. } \\
\text { Solicitante: Universidad de } \\
\text { Cádiz y Universidad de } \\
\text { Granada. }\end{array}$ & Análisis cinemático & Sensor fotodetector. \\
\hline Grenfell y col., (2010). & $\begin{array}{l}\text { Monitoring sports. } \\
\text { Patente nacional. }\end{array}$ & $\begin{array}{l}\text { Variables fisiológicas } \\
\text { y análisis cinemático. }\end{array}$ & $\begin{array}{l}\text { Pulsómetro, } \\
\text { acelerómetro y } \\
\text { GPS. }\end{array}$ \\
\hline $\begin{array}{l}\text { Irlam J.C. y } \text { Irlam } \text { L.J. } \\
\text { (2010). }\end{array}$ & $\begin{array}{l}\text { Motion analysis device for } \\
\text { sports. } \\
\text { Patente nacional. }\end{array}$ & $\begin{array}{l}\text { Variables fisiológicas } \\
\text { y análisis cinemático. }\end{array}$ & $\begin{array}{l}\text { Pulsómetro, } \\
\text { acelerómetro } \\
\text { triaxial y GPS } \\
\end{array}$ \\
\hline Molyneux y col., (2010). & $\begin{array}{l}\text { Athletic performance } \\
\text { monitoring systems and } \\
\text { methods in a team sports } \\
\text { environment. } \\
\text { Patente nacional. }\end{array}$ & Análisis cinemático. & $\begin{array}{l}\text { Sensor } \\
\text { acelerómetro. }\end{array}$ \\
\hline González y Ruiz, (2010). & $\begin{array}{l}\text { Sistema portátil de valoración } \\
\text { de la capacidad de salto } \\
\text { vertical. } \\
\text { Patente internacional. } \\
\text { Solicitante: Universidad de } \\
\text { Cádiz. }\end{array}$ & $\begin{array}{l}\text { Capacidad de salto } \\
\text { vertical }\end{array}$ & Sensor eléctrico. \\
\hline Fernández y col., (2011). & $\begin{array}{l}\text { Sistema de corrección } \\
\text { postural de la columna }\end{array}$ & $\begin{array}{l}\text { Medición postural de } \\
\text { la columna vertebral. }\end{array}$ & $\begin{array}{l}\text { Sensores } \\
\text { giróscopos, }\end{array}$ \\
\hline
\end{tabular}




\begin{tabular}{|c|c|c|c|}
\hline & $\begin{array}{l}\text { vertebral. } \\
\text { Patente nacional. } \\
\text { Solicitante: Autor. }\end{array}$ & & acelerómetros. \\
\hline Yu y col., (2011). & $\begin{array}{l}\text { Sports training analyzing } \\
\text { system based on digital field } \\
\text { and high-speed image. } \\
\text { Patente nacional. } \\
\text { Solicitante: Shanghay } \\
\text { University of Sport. }\end{array}$ & Análisis cinemático. & $\begin{array}{l}\text { Cámaras de alta } \\
\text { velocidad }\end{array}$ \\
\hline Adidas, (2012) & $\begin{array}{l}\text { System and methods for real- } \\
\text { time physiological } \\
\text { monitoring. } \\
\text { Patente nacional. }\end{array}$ & $\begin{array}{l}\text { Medición variables } \\
\text { fisiológicas y análisis } \\
\text { postural }\end{array}$ & $\begin{array}{l}\text { Sensores de } \\
\text { posición y } \\
\text { acelerometría }\end{array}$ \\
\hline
\end{tabular}

\section{Conclusiones}

En el presente artículo de revisión y tras una búsqueda bibliográfica, utilizando las plataformas digitales y bases de datos Esp@cenet, Invesnes y Google Patent, se han seleccionado un total de 26 patentes y modelos de utilidad relacionadas con la biomecánica del deporte, de las cuáles 13 de ellas son de origen español. Teniendo en cuenta las patentes españolas consultadas, se ha observado que solo dos de ella han solicitado el registro internacional, para su protección dentro de los países adscritos al tratado PCT.

La O.E.P.M. ofrece la posibilidad de registrar y divulgar el desarrollo de las distintas invenciones mediante la creación de patentes y modelos de utilidad, donde cualquier persona física o jurídica puede presentar su solicitud. Actualmente, en España, cada vez son más numerosos los investigadores comprometidos con la investigación y la innovación, desarrollándose dispositivos de valoración biomecánica dirigidas a la mejora de la evaluación y análisis del rendimiento deportivo; sin embargo, aún son muy escasos los que llegan presentar solicitud de patente con vistas a su comercialización o como cesión de sus derechos de explotación.

La creación de nuevos desarrollos e instrumentos de valoración en el campo de la biomecánica del deporte es fundamental para el avance de esta disciplina científica, siendo cada vez más numerosas las instituciones públicas y privadas que ponen a disposición de los distintos investigadores y docentes medios administrativos para la solicitud de patentes fruto de su labor de investigación e innovación.

\section{Bibliografía}

Adidas A.G. (2012). System and methods for real-time physiological. Alemania, EP2417905A1 (A61B/500) European Patent Application. Presentación Solicitud: 17.06.2005 Publicación: 15-2-2012.

Aguado, X. (1993). Eficacia y técnica deportiva. Barcelona: INDE.

Aguado, X.; Izquierdo, M., y González, J.L. (1997). Biomecánica fuera y dentro del laboratorio. León: Universidad de León.

Alan-Rose, G. (2007). IR System for kinematic analysis. United States. US 2007/0207873. Publicación: 6-9-2007.

Braune, W., \& Fischer, O. (1895). Der Gang des Menschen [Human gait]. Abhandlungen der Konichlich Sachsischen Gesellschaft der Wissenschaften, 21, 25, 26, y 28 (6). 
Bosco, C.; Luhanen, P., \& Komi, P.V. (1983). A simple method for measurement of mechanical power in jumping. European journal of applied physiology and occupational physiology, 50, 273-282.

Fernández, M.; López, A., y Ruiz, J.A. (2011). Sistema de indicación y supervisión en tiempo real de la corrección postural de la columna vertebral y aplicaciones que requieran análisis cinemático o dinámico. España, ES2364172A1 (A61B 5/11-G01S 11/00) Patente. Presentación Solicitud: 02.12.2010 Publicación: 26.08.2011.

Ferro, A. (2004). Caja estanca con mini cámara de video. España, ES1056640U (H04N 7/18- A63B 69/12) Modelo de Utilidad. Presentación Solicitud: 28.01.2004 Publicación: 16.04.2004.

Ferro, A. (2012). Biolasersport. Marca Nacional no3019808/9. Boletín Oficial de la Propiedad Industrial (B.O.P.I.). Fecha de Publicación: 12.06.2012.

Ferro, A., y Floria, P. (2010). Sistema de análisis cinemático en tiempo real para entrenamientos y competiciones deportivas. Universidad de Politécnica de Madrid y Universidad Pablo Olavide de Sevilla, España, ES2331170A1 (A61B 5/11-G01S 11/00) Patente no 2009000134. Presentación Solicitud: 19.01.2009 Publicación: BOPI: 22.12.2009.

Glover, M.S., \& Glover, S.J. (2003). Optical height measurement usable for high jump athletes and pole vaulters. Inglaterra GB2388187A. Patente. Presentación Solicitud: Fecha Publicación: 05.11.2003.

González, J.L.; Guerrero, J.M.; Mora, J.; Gómez, D., y Quirós A. (2004). Sistema de medición vía ultrasonidos de desplazamientos, y determinación de velocidades y aceleraciones durante la actividad física y deportiva. Universidad de Cádiz, España, P200400748. Patente. Presentación Solicitud: 26.03.2004.

González, J.L. (1994). Pulsador plantar perfeccionado. Modelo de Utilidad. España U9400420. BOPI, 1 de julio de 1994, no 2574.

González, J.L. (1996). Alternativa instrumental al test repeat jump de Bosco: el Pulsador Plantar Perfeccionado. Registro de la Propiedad Intelectual.: 1997 / 6205 Sección 1a. Clase de obra: Libro científico. Número de R.P.I. LE398 Junta de Castilla y León.

González, J.L.; Palma, A.J.; Carvajal, M.A.; Ruiz, P.; Mora, J., y Martínez, A. (2010). Sistema de medición de parámetros temporales de la marcha, la carrera y el salto mediante fotodetectores. Universidad de Cádiz- Universidad de Granada. PCT/ES2009/000469. Patente P.C.T. WO2010/031886A2. Presentación Solicitud: 19.09.2008. Publicación: 25.03.2010.

González J.L., y Ruiz, P. (2010). Sistema portátil de valoración de la capacidad de salto vertical. Universidad de Cádiz. P200900414 P.C.T./ES2010/000059. Patente P.C.T. Presentación Solicitud: 13.02.2009. Publicación: 10.09.2010.

Grenfell, R.; Zhang, K.; Mackintosh, C.; James, D. \& Davey, N. (2010). Monitoring sports. Australia, US 7715982 B2. Publicación: 11-5-2010.

Hutchings, L.J., (2000). System and Method for Measuring Movement of Objects. Aceleron Technologies. Estados Unidos US6122960 (G01P15/08) Patente. Presentación Solicitud: 16.12.1998. Publicación: 26.09.2000.

Irlam, J.C., \& Irlam, L.J. (2010). Motion analysis device for sports. Great Britain, US 2010/0204952 A1. Publicación: 12-8-2010.

Izquierdo, M. (2008). Biomecánica y bases neuromusculares de la actividad física y el deporte. Madrid: Editorial Médica Panamericana. 
Izquierdo, M.; Llarrión, J.L., y Santamaría, J.A. (2007). Sistema de monitorización del movimiento del ser humano. España, ES2264645A1 (G01C 21/16) Patente. Presentación Solicitud: 23-06-2005. Publicación: 01.01.2007.

Kenneth, J. \& Anderson, G. (1995). Perfomance Measuring Footwear. Estados Unidos, US5720200 (G02M1900) Patente. Presentación: 24.02.1992 Publicación: 06.06.1995

Kropelnitski, E. (1974). Jump Measuring Device US3795396A (A63b69/00). Patente. Presentación Solicitud: 23.06.1972. Publicación: 05.03.1974.

Ley Española de Patentes L.P.E. (1986): Ley 11/1986, de 20 de marzo, BOE núm. 73, de 26 de marzo de 1986.

López, J.E.; Muñoz, M.; Orrite, C.; Pérez, J.M., y Santos, R. (1999). Sistema portátil para el análisis estático y dinámico del apoyo del pie. Meditel Ingeniería Médica. España, ES 2131002A1 (A61B5/103; A61B5/103) Patente. Presentación Solicitud: 23.06.1997 Publicación: 01.07.1999.

López, J.R. (1978). Saltómetro digital. Cuba, CU34369A (G01C 21/16) Patente. Presentación Solicitud: 10.08.1975. Publicación: 09-08-1978.

Molyneux, J.; Weast, A.B., \& Burroughs, B.S. (2010). Athletic performance monitoring systems and methods in a team sports environment. United States, US 2010/0184564 A1. Publicación: 22-7-2010.

Morante, J.C.; Paz, M.; García J., y Redondo, J.C. (2005). Sistema telemétrico de cronometraje con fotocélulas láser. España, ES200400137 (G07C 1/24, A63B 71/06) Patente. Presentación Solicitud: 23.01.2004 Publicación: 01.10.2005.

Case J.R. Charles W., \& Martin Jason P. (2007). Multi-sensor monitoring of the athletic performance. Nike Inc. Estados Unidos, US0287596A1 (A63B 69/00) Patente Internacional. Presentación Solicitud: 17.12.2007 Publicación: 13.12.2007.

Oficina Española de Patentes y Marcas $(2012$ a). O.E.P.M.: Inicio. http://www. oepm.es/es/index.html [Consulta: 15 abril 2012].

Oficina Española de Patentes y Marcas (2012 b). Base de datos Espacenet. http://lp.espacenet.com/_[Consulta: 22 marzo 2012].

Oficina Española de Patentes y Marcas $(2012$ c). Modelos de utilidad. http://www.oepm.es/es/invenciones/modelo_utilidad/ [Consulta: 26 Marzo 2012].

Oficina Española de Patentes y Marcas (2012 d). Manual informativo para los solicitantes de patentes. http://www.oepm.es/es/invenciones/index.html [Consulta: 22 Marzo 2012].

Oficina Española de Patentes y Marcas (2012 e) Programa solicitud vía electrónica de patentes: Online Filing 5.0.4

https://sede.oepm.gob.es/eSede/es/invenciones/descargaDeProgramas. html [Consulta: 7 Marzo 2012].

Oficina Española de Patentes y Marcas (2012 f).

http://www.oepm.es/es/propiedad_industrial/propiedad_industrial/que_se_puede_prote ger_y_como/marcas_y_nombres_comerciales/index.html [Consulta: 21 J unio 2012 ].

Oficina Española de Patentes y Marcas (2012 g). Solicitud de Patente Internacional PCT http://www.oepm.es/es/propiedad_industrial/propiedad_industrial/que_se_puede_prote ger_y_como/solicitud_de_patente_internacional_pct/ [Consulta: 21 Junio 2012].

Page del Pozo, A.; Vera, P.; Victor, J.; Verde, V.; Moraga, R.; García, C., y Tortosa, F. (1994). Raquímetro Extensométrico Universidad Politécnica de Valencia. Instituto Biomecánica de Valencia. España, ES2048 676 (A61B 5/103) Patente. Presentación Solicitud: 28.09.92 Publicación: 16.03.94. 
Pérez, P., y Llana, S. (2007). La instrumentación en la biomecánica deportiva. J ournal of Human Sport and Exercise, 2(2), 26-41.

Soler, C.; Moraga R.; García, C., y Miralles, F. (1995). Plantilla instrumentada para la medición de presiones. Universidad Politécnica de Valencia. Instituto Biomecánica de Valencia. España, ES2070692A2 (G01C22/00) Patente. Presentación Solicitud: 17.11.1992 Publicación: 01.06.1995.

Soler, C.; Moraga, R.; García, C.; Comin, M.; Llobet, R., y Sánchez, J. (1995). Podometry system. Univ. Politécnica de Valencia. Instituto Biomecánica de Valencia. España, ES2070693A2 (G01C11/00) Patente. Presentación Solicitud: 17-11-1992 Publicación: 01.06.1995.

Tipton, S.M.; Hackworth, M., y Willson, K. (2001).Vertical Jump Measuring Device. University of Tulsa 6181647 (G04B 4700) Patente. Presentación Solicitud: 16.11.1998 Publicación: 30.01.2001.

Vera, P. (1989). Técnicas de análisis en biomecánica deportiva: estado actual y perspectivas. Jornadas Unisport sobre tecnología del deporte. Unisport. Málaga.

Viladot, A. (1992). La Biomecánica del aparato locomotor en España. Biomecánica, vol. 1, 9-18.

Yu, L.; Yining, S.; Shengnian, Z., \& Xianjun, Y. (2011). Sports training analyzing system based on digital field and high-speed image. CN201823266U (A63B6900) Patente. Presentación Solicitud: 08.04.2010 Publicación: 11.05.2011. 